\title{
La inserción internacional de la Argentina. ¿Hacia un proceso de diversificación exportadora?
}

\author{
Marta Bekerman y Federico Dulcich
}

RESUMEN

En este trabajo se analiza hasta qué punto la gran expansión de las exportaciones argentinas a partir del año 2003 obedeció solo a condiciones externas favorables y cuál fue el comportamiento de las manufacturas industriales. Se observa que el patrón de especialización internacional no sufrió grandes modificaciones a nivel de los grandes rubros, pero tanto los productos primarios como las manufacturas de origen agropecuario, que explican gran parte del superávit comercial, muestran modificaciones significativas en su composición. Asimismo, se produjo una consolidación del comercio regional y un desplazamiento en favor de China de socios tradicionales como la Unión Europea y los Estados Unidos de América. Las manufacturas industriales mantienen una marcada desventaja comparativa, pero también un incipiente desarrollo competitivo en algunos sectores de elevado contenido tecnológico, como maquinaria agrícola y bombas y compresores, así como una pronunciada competitividad ya adquirida en tubos sin costura para petróleo y gas.

PALABRAS CLAVE

CLASIFICACIÓN JEL

AUTORES
Comercio internacional, exportaciones, diversificación de las exportaciones, productos industriales, productos agrícolas, productos manufacturados, competitividad, estadísticas comerciales, Argentina

F10, F15, F63

Marta Bekerman es directora del Centro de Estudios de la Estructura Económica (cenes) de la Facultad de Ciencias Económicas de la Universidad de Buenos Aires, e investigadora principal del Consejo Nacional de Investigaciones Científicas y Técnicas (CONICET). marbekerman@gmail.com

Federico Dulcich es investigador del Centro de Estudios de la Estructura Económica (cenes) de la Facultad de Ciencias Económicas de la Universidad de Buenos Aires, y becario de investigación del Consejo Nacional de Investigaciones Científicas y Técnicas (conicET). federicomd2001@yahoo.com.ar 


\section{I}

\section{Introducción}

Durante el período posterior a la convertibilidad, en la Argentina se registraron altos niveles de crecimiento que fueron acompañados de resultados positivos del balance comercial. Esto hizo posible implementar una política de servicio de la deuda que redujo ostensiblemente los niveles de la deuda externa en relación con el producto, lo que otorgó al balance comercial un papel muy importante para definir el saldo de la cuenta corriente. De allí la relevancia de consolidar un patrón de inserción comercial internacional que asegure un crecimiento sostenido, sin que se vea limitado por la restricción externa.

Por otra parte, el perfil de especialización en el comercio internacional es determinante de la estructura económica. La posibilidad de desarrollar sectores de alto valor agregado puede permitir niveles salariales más elevados, así como mayores excedentes que posibiliten la implementación de políticas públicas de redistribución del ingreso, con mejores servicios de salud y educación. Por eso, no puede eludirse la realización de un debate profundo acerca de las tendencias recientes que muestra el patrón de especialización en la Argentina.

A partir del año 2003, el país evidenció una marcada expansión de sus exportaciones. ¿A qué se debe esta situación que parece haber desplazado, al menos por un cierto período, la restricción externa? ¿Hasta qué punto dicha expansión obedece solo a condiciones externas favorables? ¿Cuál fue la repercusión de esas condiciones en el patrón de especialización global de la economía argentina, y sobre todo en el comportamiento de las manufacturas industriales? ¿Es posible identificar rupturas y continuidades dentro de ese patrón? En este trabajo se apunta a responder estas preguntas.

Para comenzar, se ofrece un breve desarrollo del concepto de patrón de especialización y su relevancia teórica, así como su evolución histórica (sección II). Posteriormente, se presentan los principales cambios que tuvieron lugar en el contexto macroeconómico durante la última década (sección III), para luego analizar la evolución experimentada por las ventajas comparativas reveladas a nivel de los distintos rubros y principales socios comerciales, tomando también en cuenta el papel jugado por el mejoramiento en los términos de intercambio (sección IV). En la sección V se analiza el comportamiento de las manufacturas de origen industrial (MOI) a través de la evolución que registran las ventajas comparativas reveladas, considerando un balance comercial industrial equilibrado para esta clasificación para los efectos de apreciar las variaciones relativas que mostraron los distintos sectores dentro de dichas manufacturas. Enseguida, se analizarán los resultados obtenidos en términos de inserción internacional de las MOI en relación con el contenido tecnológico sectorial y su brecha con los procesos técnicos de frontera internacional (sección VI). Finalmente, se presentan las conclusiones (sección VII).

\section{II}

\section{El patrón de especialización y su relevancia en términos teóricos}

La división internacional del trabajo y la consolidación del capitalismo como forma social de producción a nivel planetario abrieron el debate teórico en torno de la especialización de las distintas naciones dentro del naciente mercado mundial, y del papel que este desempeña en los niveles de bienestar de los individuos involucrados. Este concepto ha sido abordado por distintas escuelas teóricas interesadas en su estudio, tanto con respecto a cuestiones analíticas como a las controvertidas derivaciones de política que pueden desprenderse de su análisis.

Diferenciándose del punto de vista neoclásico basado en el modelo de Heckscher-Ohlin (Appleyard y Field, 1997), fueron surgiendo distintos enfoques teóricos alternativos en que se enfatizan nuevas fuentes de ventajas comparativas y se atribuye al patrón de 
especialización una marcada relevancia respecto del sendero de crecimiento de una nación.

En la nueva teoría del comercio internacional, en la teoría del crecimiento endógeno y en diferentes corrientes neoschumpeterianas se hace hincapié, respectivamente, en los problemas de las economías de escala, la existencia de factores reproducibles con rendimientos no decrecientes (básicamente lo que denominan capital humano), los efectos de derrame entre industrias y en las diferencias internacionales en materia de conocimiento y capacidad tecnológica (Bekerman y Sirlin, 1999).

Sobre la base de esta concepción de la inserción internacional, en que se otorga a las ventajas comparativas un carácter dinámico, surge una literatura más reciente con distintos argumentos en que se enfatiza la importancia de la diversificación exportadora. En primer lugar, dicha diversificación ayuda a reducir la volatilidad del ingreso de divisas por exportaciones y, por lo tanto, del crecimiento de la economía (Agosin, 2009). Esto es sobre todo relevante para los países en desarrollo, que suelen tener escaso acceso al mercado financiero internacional para cubrir déficits coyunturales de la cuenta corriente y que, por lo general, son muy dependientes de bienes de capital e insumos importados.

Por otra parte, la diversificación exportadora implica una diversificación productiva que permite que los agentes locales "descubran" las ventajas comparativas inexploradas de su economía, donde los pioneros exportadores les muestran el camino a los continuadores (Hausmann y Rodrik, 2003). En la medida en que los países presentan una canasta de exportaciones de alta calidad, basada en artículos más sofisticados, registran un crecimiento posterior más alto que los países que no lo hacen (Rodrik, 2005). En este contexto, es muy importante que el proceso de migración de productores hacia nuevos sectores no vea bloqueado el acceso por excesivas barreras (patentes, elevadas escalas mínimas eficientes, entre otras). Estos procesos de diversificación productiva generan una gama de externalidades (incremento de la productividad debido a la especialización productiva de los agentes, aumento de la calificación de la mano de obra, y otras) que repercuten positivamente en el crecimiento. Esto conduce a que algunos autores defiendan el papel del Estado "guiando al mercado" en el descubrimiento de nuevas capacidades (Wade, 1989).

En síntesis, existe un amplio consenso en que el patrón de especialización es determinante de la estructura económica y, por consiguiente, de la sustentabilidad y el nivel de crecimiento de largo plazo de una economía. A partir de allí los distintos sectores ofrecen diferentes niveles de derrames tecnológicos, así como una disímil potencialidad de captar ganancias extraordinarias mediante la diferenciación de procesos o productos, y por ende de acumular capital y generar posteriores aumentos de productividad. Estas divergencias en la evolución de la productividad inciden en la potencialidad de elevar los salarios reales, así como en la generación de mayores excedentes que hagan posible la implementación de políticas públicas de redistribución del ingreso.

En las próximas secciones se analizará el contexto macroeconómico y la evolución de los patrones de especialización de la economía argentina durante la última década.

\section{III}

\section{Contexto macroeconómico}

La caída de la convertibilidad, que implicó la devaluación del tipo de cambio real, generó una transformación crucial en la política macroeconómica de la Argentina. El período inicial de incertidumbre y de contracción en la demanda interna fue seguido, a la salida de la crisis de 2001-2002, de un proceso de recuperación económica que hizo posible inaugurar una etapa de crecimiento sostenido sin perjudicar a la balanza comercial.

Esto fue así debido a que ese proceso de recuperación se basó no solo en la recuperación de la demanda interna, sino también en una notable expansión de las exportaciones y en un proceso de sustitución de importaciones. Por ende, lo que tal vez puede ser considerado como un rasgo macroeconómico muy destacable de la posconvertibilidad es el desplazamiento de la restricción externa al crecimiento. La economía creció a altas tasas durante ocho años seguidos -con una única interrupción en 2009-, en tanto que se logró mantener un abultado superávit comercial (véase el gráfico 1).

A partir del año 2001 se observa un cambio estructural en la composición de la demanda final en favor de una mayor participación de las exportaciones 
GRÁFICO 1

Argentina: evolución del PIB y de los flujos de comercio exterior, 1998-2010 (En millones de dólares corrientes)

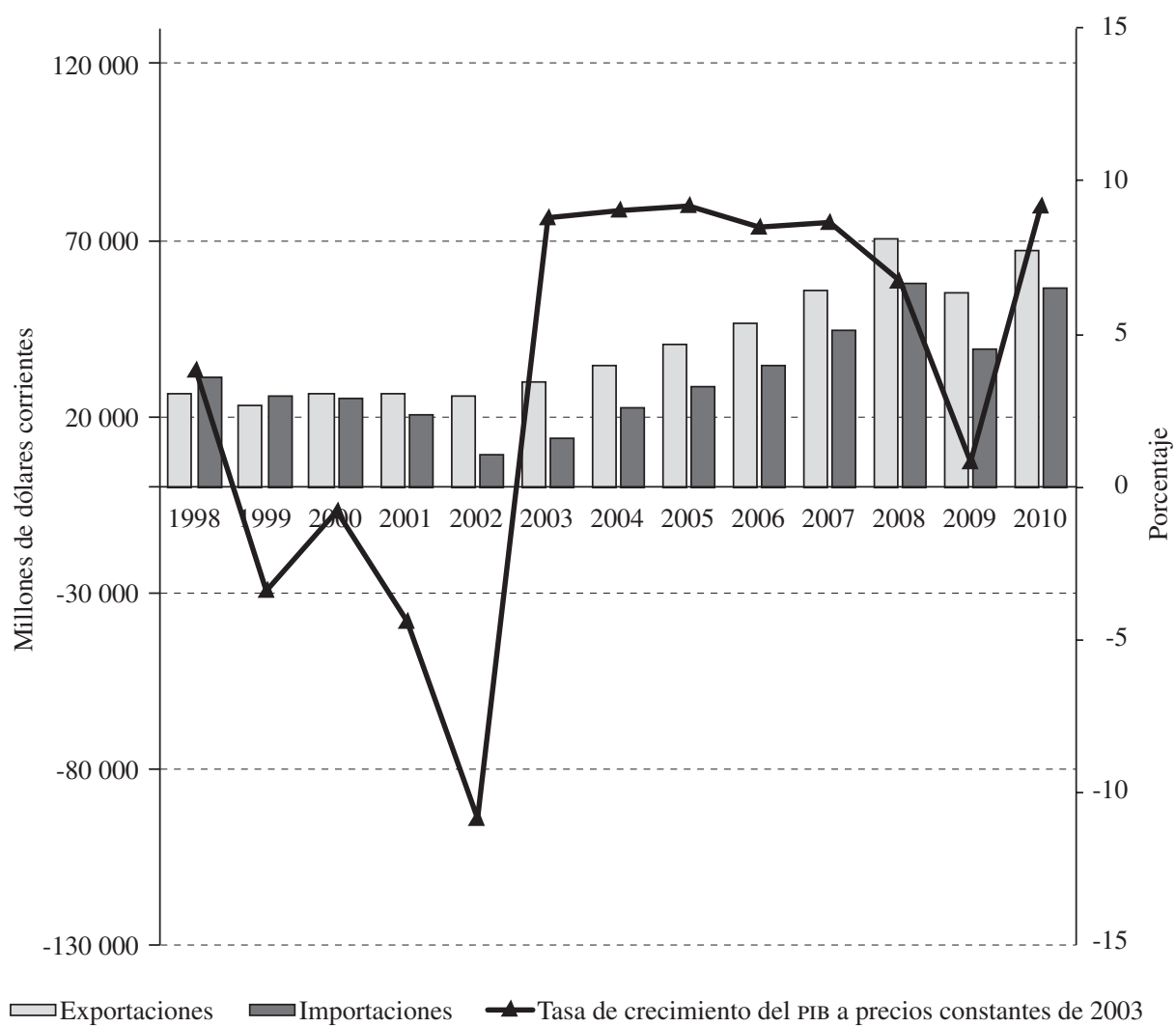

Fuente: elaboración propia sobre la base de Instituto Nacional de Estadística y Censos (INDEC) y Base de datos estadísticos sobre el comercio de mercaderías (COMTRADE).

PIB: producto interno bruto.

y de la inversión, en detrimento del consumo público y privado. Las ventas externas pasaron de representar el 9,3\% de la demanda agregada durante el período $1995-$ 1997 al 21,7\% entre 2003 y 2005, participación que luego se fue reduciendo lentamente ante la recuperación del consumo público y, especialmente, de la inversión ${ }^{1}$.

Katz y Bernat explican que los cambios de regímenes macroeconómicos iniciados en fases contractivas, como el ocurrido en la Argentina hacia fines de 2001, dan origen a estas transformaciones en la composición de la demanda agregada, debido a que afectan de manera disímil a los distintos sectores según sea su brecha respecto de los procesos técnicos de frontera. Aquellos más cercanos a la frontera técnica internacional pueden volcar sus

\footnotetext{
${ }^{1}$ En 2002, la inversión representaba el 10,4\% de la demanda agregada y actualmente representa el $19 \%$ de esta.
}

excedentes en el mercado externo, ante la caída del nivel de consumo interno. En cambio, los relativamente menos productivos no pueden competir internacionalmente y son más afectados por la recesión, con una mayor salida de empresas (Katz y Bernat, 2011). Como resultado de este proceso cabe esperar la generación de un mayor potencial exportador, que ayuda a explicar por qué la inserción externa en la Argentina pasó a jugar un papel mucho más relevante que en la década pasada como motor de la demanda agregada. Pero también señala que estas situaciones no afectaron de igual manera a todos los sectores industriales. Sus respuestas estuvieron influenciadas por distintos condicionantes, especialmente por los niveles de competitividad que presentaban antes de la crisis. De esta forma, se vuelve importante observar cuáles fueron las transformaciones experimentadas en la inserción internacional de los grandes rubros y sectores industriales, lo que se abordará en las próximas secciones. 


\section{IV}

\section{Inserción comercial exterior por grandes rubros y principales socios comerciales}

\section{Cuestiones metodológicas}

a) Índice de ventajas comparativas reveladas $(\mathrm{VCR})^{2}$

Para definir el patrón de especialización de una economía se deben estudiar simultáneamente las exportaciones y las importaciones; en consecuencia, se toma como variable de análisis el saldo comercial sectorial. Pero los saldos comerciales deben ser normalizados para descontar el efecto de aquellos factores coyunturales (especialmente los macroeconómicos) que conducen a superávits o déficits comerciales globales.

Es por ello que para el análisis del patrón de especialización global se trabaja con el índice VCR, de manera que:

$$
\begin{gathered}
V C R_{i}=\left[\left(X_{i}-M_{i}\right)-(X-M) *\left(X_{i}+M_{i}\right) /(X+M)\right] \\
* 1000 /(X+M)
\end{gathered}
$$

donde $\left(X_{i}-M_{i}\right)$ es el saldo comercial observado en el sector $i, \mathrm{y}(X-M) *\left(X_{i}+M_{i}\right) /(X+M)$ es un valor teórico que representa el componente sectorial de $i$ en el superávit o déficit global.

Las ventajas comparativas reveladas representan, entonces, balances comerciales sectoriales normalizados, correspondientes a una situación hipotética de equilibrio comercial. En este sentido, constituyen un indicador de las ventajas comparativas de la nación.

Como se puede apreciar en el indicador, la forma en que se produce la "normalización" de los saldos sectoriales observados es restando de estos un componente sectorial teórico, que es estimado en función de la participación en el comercio total del comercio (exportaciones más importaciones) del sector considerado.

Este criterio implica algunos supuestos simplificadores, como por ejemplo, que los desbalances coyunturales originados en variables macroeconómicas afectan indistintamente a todos los sectores (o, más precisamente, en función de su mera participación en el comercio total). La evolución del nivel de actividad puede incidir en la evolución del indicador de VCR a

2 Este índice se basa en el desarrollado por Miotti, Quenan y Winograd (1998). partir de su repercusión disímil en el comportamiento de las importaciones y exportaciones ${ }^{3}$.

Si bien el indicador de VCR es adecuado para el análisis del patrón de especialización a nivel global, este indicador puede generar sesgos importantes para el comercio por destinos comerciales. Estos sesgos serán tanto mayores cuanto más diferentes sean las relaciones entre balance comercial y comercio total correspondientes a cada destino, por una parte, y al comercio con el mundo, por otra. En términos teóricos, el análisis de los intercambios, suponiendo comercio equilibrado, es mucho más relevante en el caso del comercio con todo el mundo que en el de los comercios bilaterales, donde puede que no existan fuerzas económicas que generen tendencias a un relativo equilibrio comercial, al menos en el corto plazo. En última instancia, el análisis del comercio por destinos introduce una cuestión nueva - la triangulación comercial — que no es captable con el indicador de VCR.

\section{b) Índice de desempeño comercial (DC)}

Ante la existencia de estos problemas, para el estudio del comercio bilateral con los distintos socios de la Argentina se ha utilizado un indicador ligeramente diferente del que hemos denominado desempeño comercial normalizado o simplemente desempeño comercial (DC):

$$
\begin{gathered}
D C_{i j}=\left[\left(X_{i j}-M_{i j}\right)-\left(X_{i j}+M_{i j}\right) *(X-M) /(X+M)\right] \\
* 1000 /(X+M)_{j}
\end{gathered}
$$

donde el subíndice $i$ representa a cada uno de los sectores, el subíndice $j$ a cada socio comercial, y la ausencia de subíndices a las exportaciones e importaciones totales.

La diferencia con el indicador de VCR (utilizado para el análisis del patrón de especialización global) es que, en este caso, en la normalización del saldo comercial sectorial (determinación del valor teórico) se sigue utilizando el balance comercial global, mientras que en el

\footnotetext{
3 Un nivel más alto de actividad puede generar una mayor presión sobre las importaciones de aquellos sectores que muestran mayores niveles de elasticidad de estas con respecto al producto. En contraposición, una situación recesiva producirá el efecto contrario, como se aprecia en la evolución del índice por grandes rubros para el período 1999-2002.
} 
resto del indicador aparecen variables correspondientes al comercio bilateral. Es decir, son desempeños comerciales correspondientes a una situación de equilibrio comercial global (y no bilateral). Esto significa que la sumatoria del valor de todos los sectores (a la que llamaremos desempeño comercial total) de este indicador para cada destino ya no será igual a cero. Un signo negativo (positivo) indicará que respecto de un determinado país se tiene - con relación a su participación en el comercio total—un déficit comercial mayor (menor) o un superávit comercial menor (mayor) que con el resto de los países. Un signo negativo en aumento durante un período podría ser consecuencia de un deterioro en determinados sectores no compensados por el comportamiento de otros.

El indicador de desempeño comercial presenta, entonces, diferencias con el de VCR. En efecto, la esencia del concepto de ventajas comparativas es la interrelación entre sectores que hace que las ventajas de unos se correspondan con desventajas de otros. En este caso, en el comercio con un país determinado pueden aparecer desempeños positivos o negativos para todos los sectores. Como divisor final de este indicador se considera el comercio total bilateral, a fin de evitar los efectos que provocan las diferentes participaciones de los distintos países en el comercio total de la Argentina y para hacer comparables los valores correspondientes al comercio con distintos socios comerciales y al comercio con todo el mundo.

\section{c) Índice de ventajas comparativas reveladas de las MOI ( $\left.V_{C O R_{M O I}}\right)$ \\ La existencia de una ostensible especialización} de la Argentina en los sectores de productos primarios (PP) y de manufacturas de origen agropecuario (MOA) determina niveles altamente negativos de VCR para los sectores de manufacturas de origen industrial (MOI) y vuelve insignificantes sus variaciones. Por eso se ha elaborado aquí un índice de ventajas comparativas reveladas propias de los distintos sectores de MOI en relación con el promedio del universo de dicho rubro utilizado en la sección V. El índice $\mathrm{VCR}_{\mathrm{MOI}}$ se conforma de la siguiente manera:

$$
\begin{gathered}
V C R_{M O I i}=\left[\left(X_{i}-M_{i}\right)-\left(X_{m o i}-M_{m o i}\right) *\right. \\
\left.\left(X_{i}+M_{i}\right) /\left(X_{m o i}+M_{m o i}\right)\right] * 1000 /\left(X_{m o i}+M_{m o i}\right)
\end{gathered}
$$

donde $\left(X_{i}-M_{i}\right)$ es el saldo comercial observado en el sector $i$ (sector que debe pertenecer a las MOI), $\left(X_{m o i}-M_{m o i}\right) *\left(X_{i}+M_{i}\right) /\left(X_{m o i}+M_{m o i}\right)$ es un valor teórico que representa el componente sectorial de $i$ en el superávit o déficit de las MOI.
Este índice es, en su estructura, análogo al de VCR, solo que en él se reemplaza el superávit o déficit global por el superávit o déficit de las MOI. Por ende, representa una normalización del saldo comercial de los distintos sectores de las MOI, considerando un equilibrio en el comercio total de las MOI. Es importante remarcar que no existen en la Argentina tendencias económicas a equilibrar el saldo comercial de las MOI, como sí existen para el caso del saldo comercial global. Sin embargo, el índice permite expresar el desempeño de un sector en relación con el comportamiento global del rubro de las MOI. Para ello, compara el saldo comercial real con el saldo comercial teórico correspondiente al sector considerado. Este último se elabora a partir de su participación dentro del comercio de las MOI (tanto en importaciones como en exportaciones), y del saldo comercial total de dicho rubro. Un índice $\mathrm{VCR}_{\mathrm{MOI}}$ positivo (negativo) implica que el saldo real de ese sector es mayor (menor) que el teórico, por lo que el superávit comercial real es mayor (menor) que el teórico (ante un superávit global en las MOI), o el déficit comercial es menor (mayor) que el teórico (ante un déficit global en las MOI). Por consiguiente, la suma en todos los sectores de las MoI del índice es nula.

\section{El comportamiento de las VCR durante la última década. Análisis por grandes rubros}

La economía argentina presenta históricamente un patrón dual de especialización. Sus fuentes de ventajas comparativas radican en la producción de productos primarios y MOA, mientras que presenta marcadas desventajas comparativas en las MOI. Durante la convertibilidad, ese patrón de especialización se vio acentuado ante la creciente apreciación del tipo de cambio real. En efecto, en ese período los productos primarios aumentaron sus ventajas comparativas sobre la base del comportamiento de los cereales y oleaginosas, y en menor medida de los pescados y mariscos sin elaborar (Bekerman y Cerdeiro, 2007). Dentro de las MOA, los alimentos para animales, aceites y grasas, por una parte, y en segundo término cueros y carnes, fueron los sectores que mostraron el mejor desempeño relativo. Podría señalarse que el sector de alimentos y bebidas consolidó su hegemonía competitiva externa y su posición dentro de la estructura industrial argentina; es así como durante la crisis de 1998-2002 fue menos afectado que otros sectores industriales dada su menor elasticidad frente al nivel de actividad interna.

$\mathrm{Al}$ analizar el comportamiento de las MOI durante la convertibilidad se pueden diferenciar los sectores en dos 
grupos. A nivel de los productos básicos (commodities) industriales, el proceso de privatización de empresas públicas dio lugar a la consolidación de ciertos grupos económicos privados, que incrementaron su poder de mercado y pudieron avanzar en un proceso de convergencia tecnológica hacia la frontera internacional. El ejemplo más claro de esta situación es el de la producción de tubos sin costura para la extracción de petróleo. En cambio, los sectores de maquinarias, aparatos electrónicos y material de transporte registraron un pronunciado déficit de competitividad, que se vio ampliado hacia finales de la década de 1990 ante el avance tecnológico mundial y la falta de promoción de actividades locales de innovación (Bekerman y Sirlin, 1999).
La evolución del índice de VCR durante la primera década de este siglo puede observarse en el gráfico 2. En términos agregados, el patrón global de especialización internacional de la Argentina no ha sufrido grandes modificaciones, mantiene una clara ventaja comparativa en productos primarios e incrementa esa ventaja en las MOA. En el caso de los productos primarios, esta ventaja se fue consolidando a partir de la incorporación de procesos técnicos de frontera internacional, como la utilización de organismos modificados genéticamente (OMG) y de siembra directa, entre otros. En el caso de las MOA, crecen sectores que se benefician del diferencial de retenciones entre su insumo (los granos u oleaginosas) y su producto final (aceites y subproductos de la molienda). Esta fuente

GRÁFICO 2

Argentina: índice de VCR por grandes rubros, 1998-2010 (Índice de valores absolutos)*

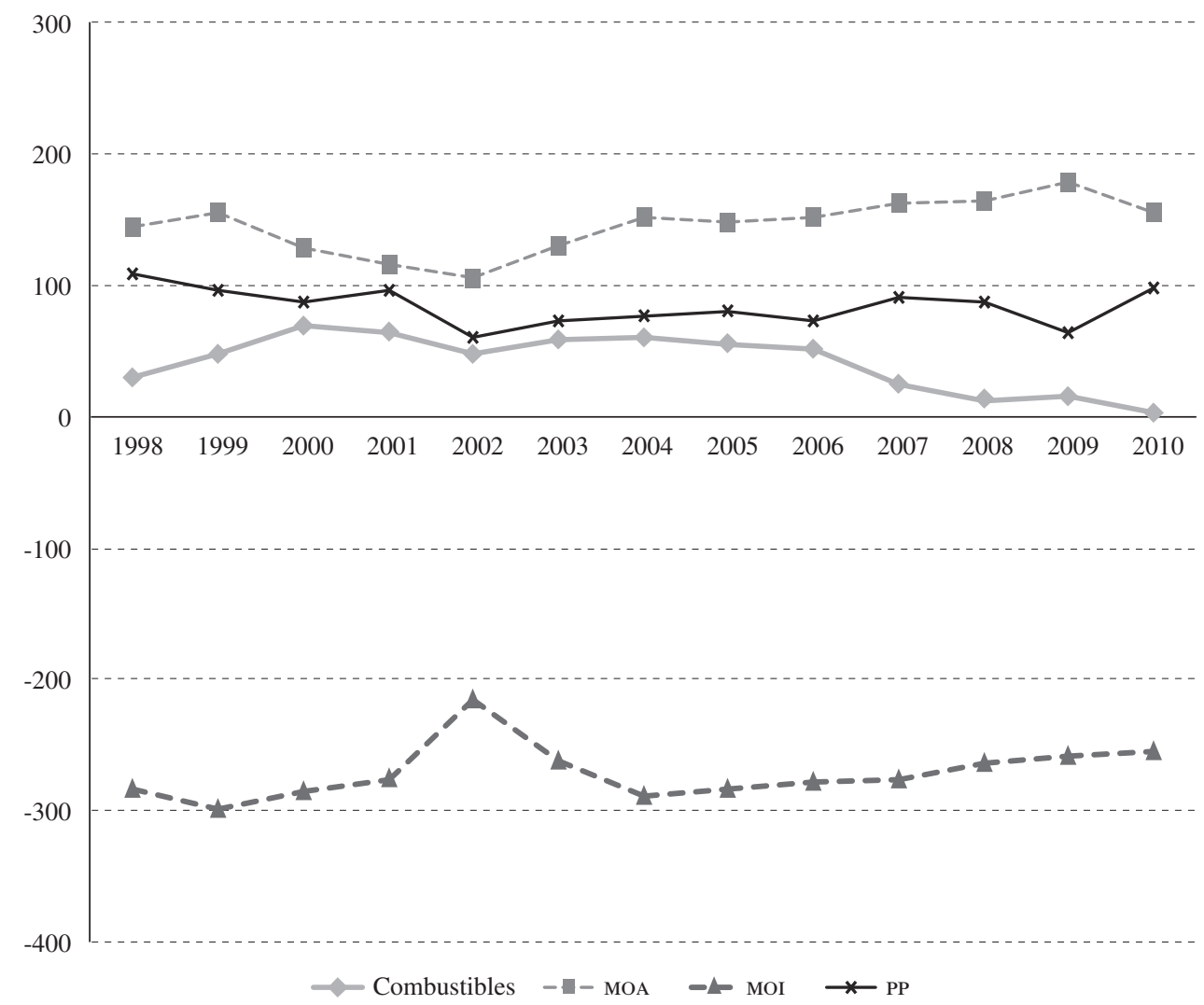

Fuente: elaboración propia sobre la base de Instituto Nacional de Estadística y Censos (INDEC) y Base de datos estadísticos sobre el comercio de mercaderías (COMTRADE).

* Cifras calculadas a partir de las ecuaciones descritas en la sección IV de este artículo.

VCR: ventajas comparativas reveladas.

MOA: manufacturas de origen agropecuario.

MOI: manufacturas de origen industrial.

PP: productos primarios. 
de ganancia extraordinaria se suma a la determinada por los procesos técnicos de frontera, y se fundamenta en la capacidad del sector primario de transferir parte de la renta de la tierra mediante el esquema de retenciones, implementado con posterioridad a la devaluación de la moneda de 2001-2002.

En cambio, en el caso de los combustibles se aprecia una tendencia decreciente durante los últimos años. Esto se explica por el notable crecimiento de las importaciones de petróleo (de 198 millones de dólares en 2003 a 2.567 millones de dólares en 2010), que produjo una caída del $59 \%$ en las exportaciones netas (1.608 millones de dólares en 2010). El crecimiento de la demanda interna (fundamentado en el crecimiento de la economía), significativamente superior al de la producción, repercutió negativamente en la inserción internacional de este sector.

Las MOI mantienen la continuidad de sus marcadas desventajas comparativas, pero estas tienden a mostrar una leve reducción durante los últimos años.

La existencia de una manifiesta correlación entre el déficit de las mor y el nivel de actividad se relaciona con el abultado peso de ciertos rubros vinculados al desenvolvimiento económico, como son los bienes de capital, los insumos y las partes y piezas ${ }^{4}$. Esto implicó que dicho déficit fuera creciente durante el período de recuperación económica, y se viera reducido durante el año 2009 a partir del impacto de la crisis internacional en el nivel de actividad interna (véase el gráfico 3).

\section{La repercusión de los términos de intercambio}

El significativo déficit comercial que presentan las MOI ha sido más que compensado durante el último lustro por un elevado superávit comercial en productos primarios y de las MOA, lo que dio lugar a la existencia de un superávit comercial global. Un determinante fundamental de ese superávit fue la mejora en los términos de intercambio a partir de un notable aumento

4 Estos rubros representan en la actualidad el $80 \%$ de las importaciones de MOI, constituyendo una participación estructural para toda la década.

GRÁFICO 3

Argentina: evolución del comercio exterior de las MOI, 1998-2010

(En millones de dólares corrientes)

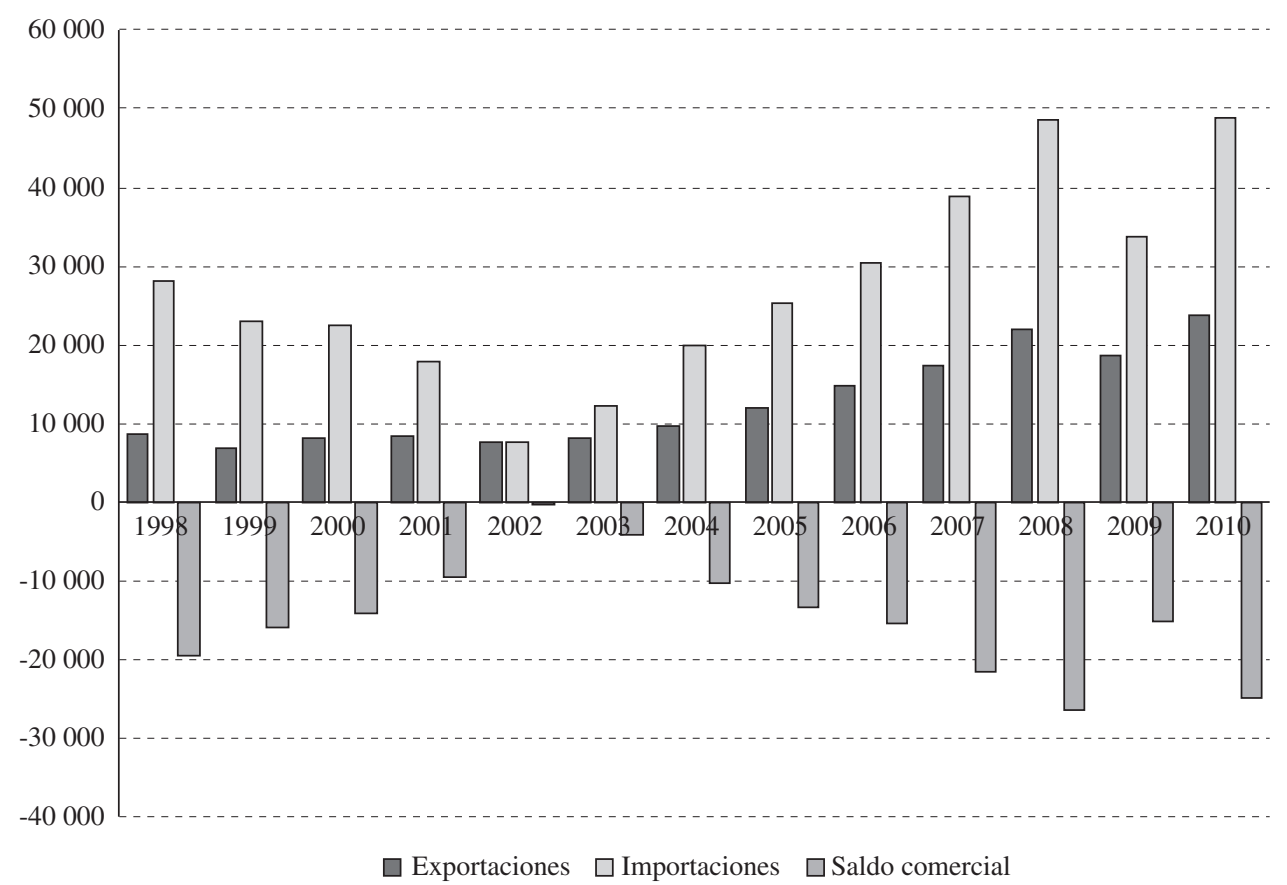

Fuente: elaboración propia sobre la base de Instituto Nacional de Estadística y Censos (INDEC) y Base de datos estadísticos sobre el comercio de mercaderías (COMTRADE).

MOI: manufacturas de origen industrial. 
en la demanda de productos alimenticios, impulsada especialmente por los mercados asiáticos.

¿Qué hubiera sucedido con el saldo comercial argentino si los precios internacionales se hubieran mantenido en los niveles del año 2003? Si se descuenta el efecto de la variación de dichos precios ${ }^{5}$ (considerando precios constantes del año 2003), se puede notar que el superávit comercial se hubiera mantenido, pero reducido a unos 2.500 millones de dólares, es decir, a niveles mucho menores que los alcanzados en los últimos años (del orden de los 13.000 millones de dólares). Esto se debe a una drástica disminución de los hipotéticos superávits de productos primarios y de las MOA en relación con los que realmente existieron a precios corrientes (véase el gráfico 4). Por ende, el alto superávit comercial actual muestra una marcada

5 Para ver los detalles metodológicos de la transformación a precios constantes de 2003, véase el número 1 del anexo II. dependencia de la evolución de los precios relativos, y expone cierta fragilidad del patrón de inserción en el mercado externo ante la posible profundización de la crisis internacional. Asimismo, cabe recordar que el balance comercial es el principal proveedor de divisas en términos de la cuenta corriente, dado que la Argentina tiene un déficit estructural en la categoría de servicios, aunque decreciente en los últimos años.

Sin embargo, es importante subrayar que, a diferencia del pasado, el saldo comercial argentino hubiera mantenido niveles positivos en un período de fuerte crecimiento, aun descontando la favorable evolución de los precios relativos internacionales que tuvo lugar a partir de $2003^{6}$.

6 Es importante señalar que en la evolución del saldo comercial mencionada no se consideran otros efectos de equilibrio general (inversión, incidencia del nivel de actividad en las importaciones, y otros ), sino que solo se analiza el efecto precio (muy significativo para el período). Considerar conjuntamente todos los efectos en el marco de un modelo de equilibrio general amerita un análisis específico, que excede los objetivos del presente trabajo.

GRÁFICO 4

Argentina: exportaciones netas promedio 2008-2010 por grandes rubros (En millones de dólares a precios corrientes y precios constantes de 2003)

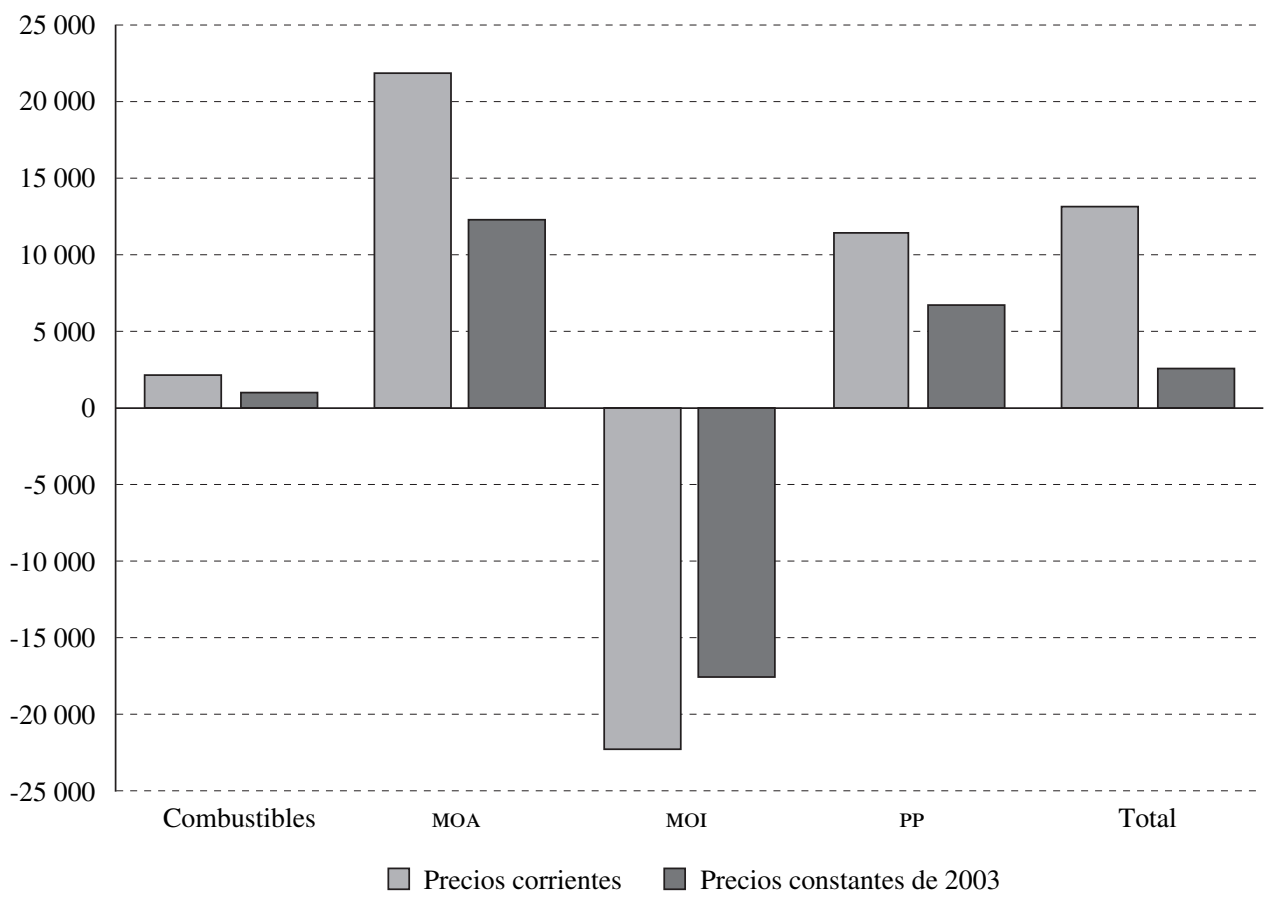

Fuente: elaboración propia sobre la base de Instituto Nacional de Estadística y Censos (INDEC), Base de datos estadísticos sobre el comercio de mercaderías (COMTRADE) y Comisión Nacional de Comercio Exterior (CNCE).

MOA: manufacturas de origen agropecuario.

MOI: manufacturas de origen industrial.

PP: productos primarios. 


\section{Comercio bilateral por rubros y principales socios comerciales}

Durante los últimos años el intercambio comercial argentino muestra profundos cambios en su vinculación con los diferentes socios comerciales. Por consiguiente, en esta subsección se analizará dicho intercambio a nivel de rubros tomando en consideración las cuatro áreas comerciales más significativas: el Brasil, China, los Estados Unidos de América y la UE-27.

El caso de los productos primarios ( $\mathrm{PP}$ ) es un claro ejemplo de la notoria transformación que se produjo en los destinos comerciales a partir de una clara sustitución de los mercados más tradicionales, como eran el Brasil y la Unión Europea, por China. La evolución del desempeño comercial con cada uno de estos destinos puede observarse en el gráfico 5.

Puede apreciarse, en efecto, un crucial desplazamiento de Europa como destino de las exportaciones de porotos de soja en favor de China ${ }^{7}$. Sin embargo, el desempeño comercial de los PP con respecto a la Unión Europea persiste en niveles elevados debido al buen desarrollo de las exportaciones de pescados ( $45 \%$ del valor exportado en PP), y de maíz (25\%). Por otra parte, se produjo una manifiesta desaceleración en las exportaciones de trigo dirigidas al Brasil, que crecieron a una tasa promedio anual del 2\% durante el lapso 1998-2009.

La situación es diferente para el caso de las MOA, donde se destaca claramente el crecimiento del desempeño comercial con la Unión Europea, que se mantiene muy superior con respecto al resto de los socios seleccionados (véase el gráfico 6). Esto se fundamenta en las elevadas exportaciones de subproductos de la molienda de soja

\footnotetext{
7 Durante el período 1998-2009 esas exportaciones dirigidas a China crecieron a un impresionante $29,5 \%$ anual, mientras que las enviadas a la Unión Europea decrecieron en un 19\%.
} GRÁFICO 5 Argentina: evolución del desempeño comercial de los productos primarios
por país, 1998-2010
(Índice de valores absolutos)*

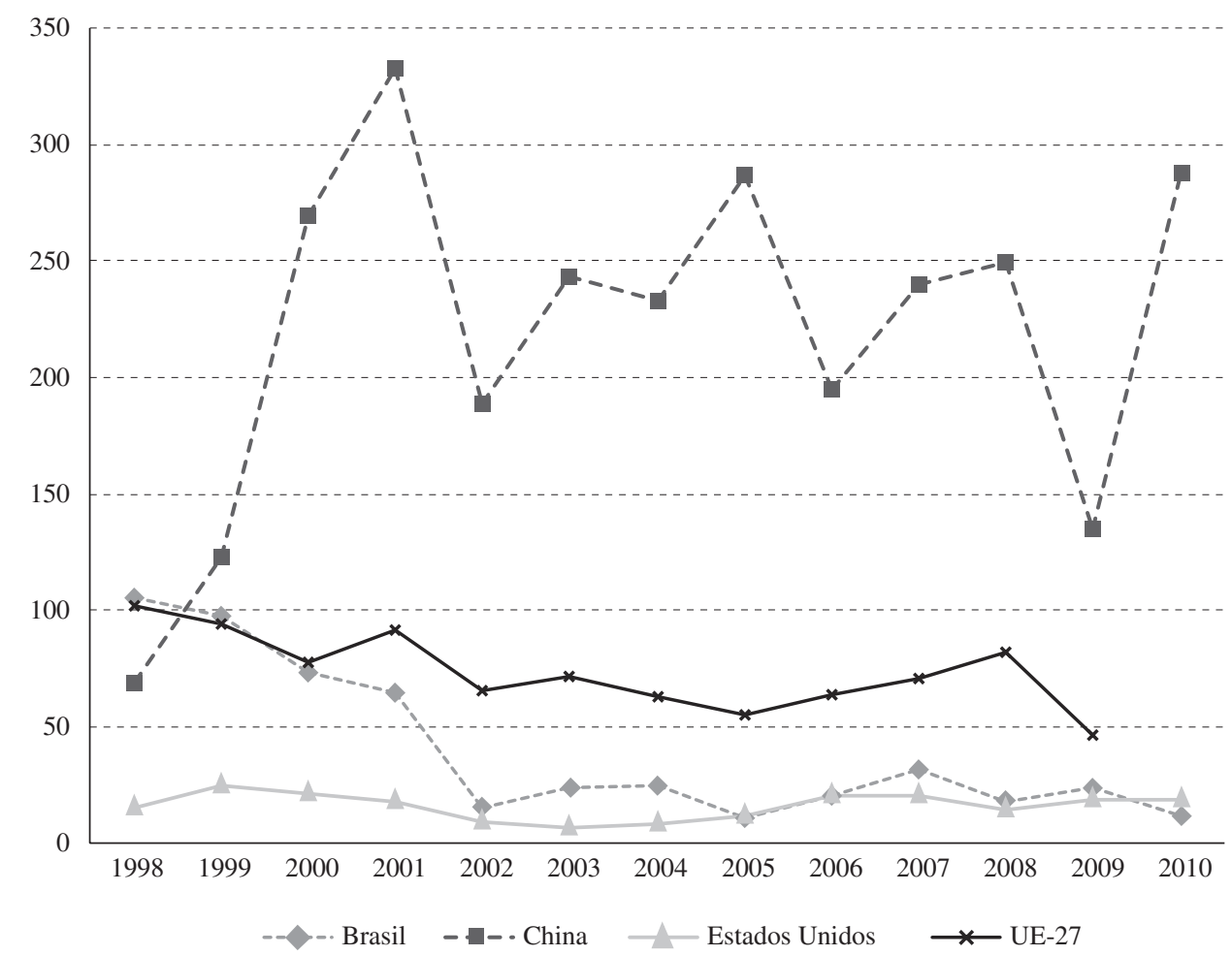

Fuente: elaboración propia sobre la base de Instituto Nacional de Estadística y Censos (INDEC), Base de datos estadísticos sobre el comercio de mercaderías (COMTRADE) y Comisión Nacional de Comercio Exterior (CNCE).

* Cifras calculadas a partir de las ecuaciones descritas en la sección IV de este artículo. 


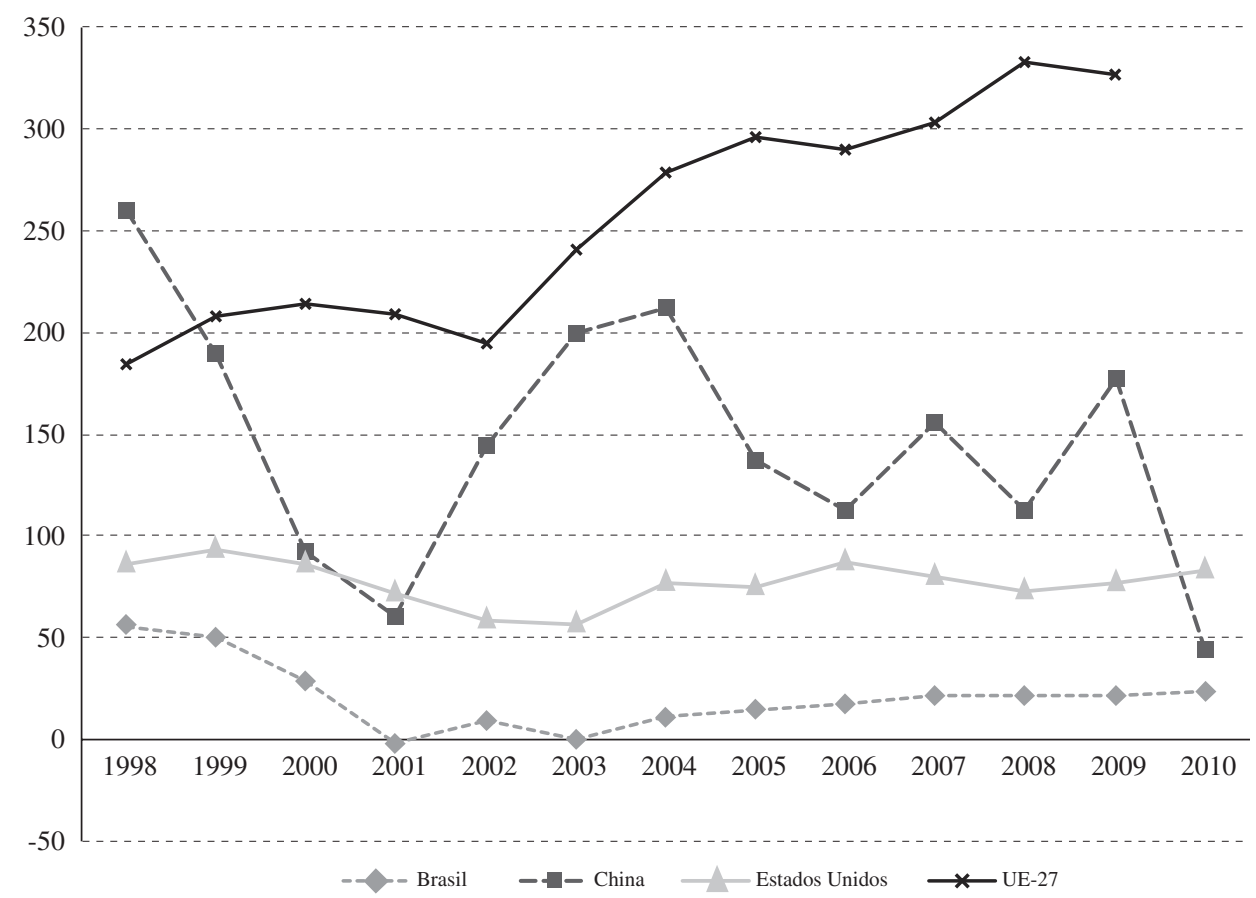

Fuente: elaboración propia sobre la base de Instituto Nacional de Estadística y Censos (INDEC), Base de datos estadísticos sobre el comercio de mercaderías (COMTRADE) y Comisión Nacional de Comercio Exterior (CNCE).

* Cifras calculadas a partir de las ecuaciones descritas en la sección IV de este artículo. MOA: manufacturas de origen agropecuario.

(pellets de soja), que son utilizados para la alimentación animal y que representaron el 54\% de las exportaciones de MOA a la Unión Europea en el período 2007-2009.

Por otra parte, se observa también un crecimiento del desempeño comercial de las MOA con respecto a China, aunque este presenta un carácter más inestable y se concentra sobre todo en un producto de la cadena sojera: las exportaciones de aceite de soja han crecido a un $31 \%$ promedio anual en toda la década (a pesar de una brusca caída en 2010), y representaron el $81 \%$ de las exportaciones de MOA a ese destino en $2007-2009^{8}$. El marcado peso del complejo sojero de las exportaciones de MOA, así como la dependencia de los mercados de la Unión Europea y China explican el alto grado de concentración del superávit comercial de las MOA.

${ }^{8}$ Sin embargo, en las exportaciones a China hay una preponderancia del poroto de soja sobre el aceite, que explica el mejor comportamiento del desempeño comercial de los productos primarios respecto de las exportaciones de MOA a dicho destino.
En cuanto a la relación con el Brasil, las exportaciones de MOA nunca presentaron elevados niveles dada la estrategia de este país de desarrollar una robusta industria de alimentos. Dichas exportaciones registran una aguda caída hacia el año 2003, debido a una drástica reducción en las exportaciones de leche en polvo, que luego se recupera sobre la base de exportaciones de harina de trigo y de malta, pero sin llegar a alcanzar los niveles de desempeño comercial de la década pasada.

En el caso de las MOI, en un contexto de un desempeño comercial bastante negativo, puede apreciarse una marcada modificación en la relación con los distintos socios comerciales. Hasta mediados de la década de 2000 , se observa un notorio deterioro en el desempeño comercial con el Brasil, que comienza a revertirse de allí en adelante, aunque conservando un carácter negativo. Las importaciones aparecen concentradas en automóviles y tractores (24\% de las importaciones), piezas para vehículos (10\%), y en teléfonos fijos, celulares y otros dispositivos de transmisión de datos $(6 \%)$, rubro que mostró un gran crecimiento en las importaciones desde 
el Brasil a partir de la recuperación económica local. Por parte de las exportaciones, se observa un manifiesto crecimiento de las automotrices durante el último lustro (55\% de promedio anual), que las condujo a triplicar su participación en las exportaciones de MOI al Brasil, lo que explica en gran medida la señalada mejoría del desempeño comercial de las MOI con respecto a dicho destino. Sin embargo, la contrapartida de este crecimiento exportador es el menoscabo en el desempeño comercial del subsector de piezas para vehículos, por lo que el resultado neto del sector sigue siendo deficitario para la Argentina.

Asimismo, los sectores de sustancias químicas básicas y maquinaria de uso especial han visto mejorar claramente su desempeño con el Brasil. Sin embargo, la maquinaria de uso especial persiste como un componente importante del déficit de MOI con dicho país, representando el 9\% de este, participación prácticamente análoga a la de fines de la década de 1990.

A partir de 2003 se inicia un ostensible deterioro en el desempeño comercial de las MOI con China, debido al incremento de las importaciones de bienes de capital, maquinarias y productos eléctricos, por una parte, y de productos químicos inorgánicos, por otra, que representan en conjunto el $60 \%$ del valor importado desde dicho país. Al mismo tiempo, se observan mejoras en el desempeño con los Estados Unidos de América y la Unión Europea (véase el gráfico 7), economías que vienen siendo desplazadas por China como proveedoras de ciertos bienes industriales (bienes de capital y maquinaria y aparatos eléctricos), y por el Brasil (teléfonos fijos y celulares, y piezas para vehículos).

GRÁFICO 7

Argentina: evolución del desempeño comercial de las MOI por país, 1998-2010 (Índice de valores absolutos)*

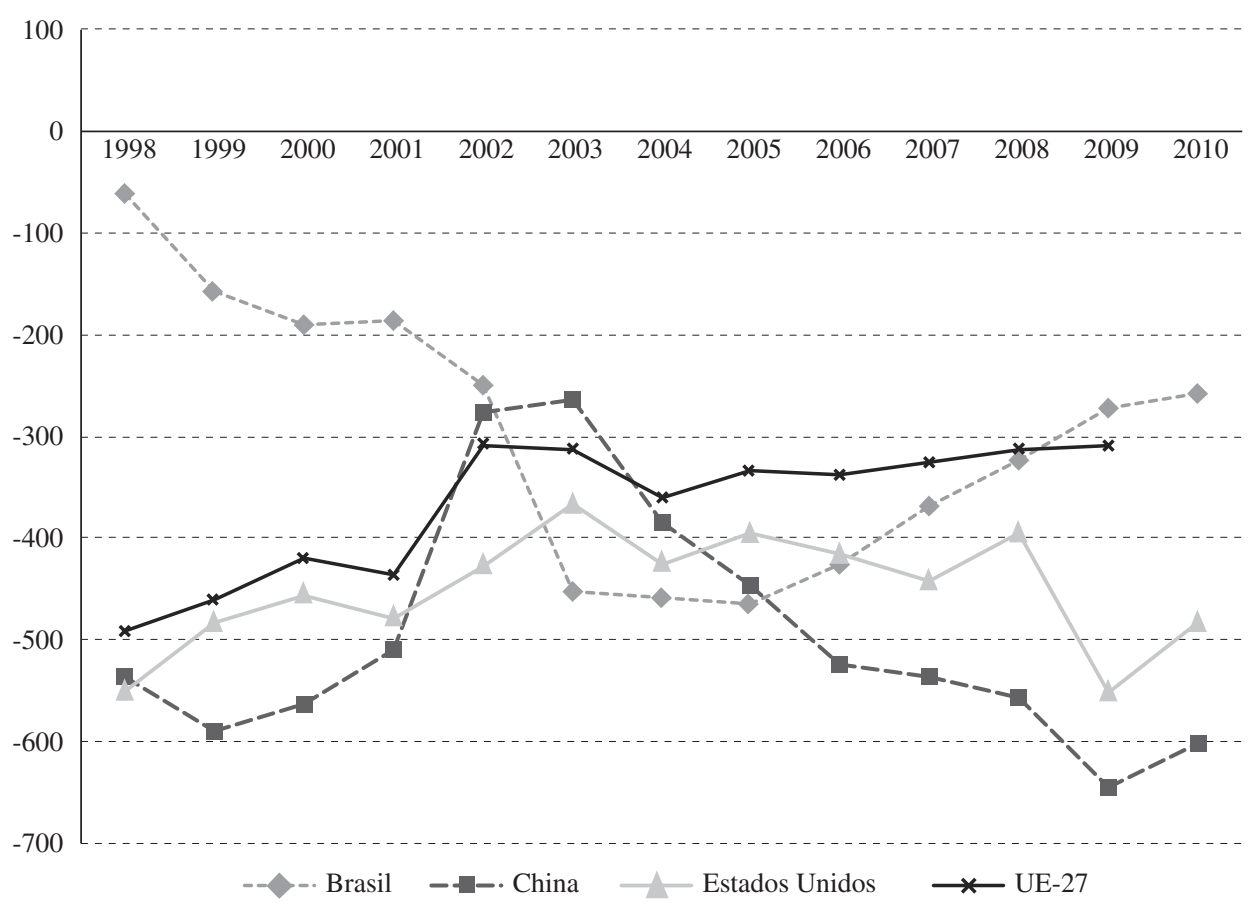

Fuente: elaboración propia sobre la base de Instituto Nacional de Estadística y Censos (INDEC), Base de datos estadísticos sobre el comercio de mercaderías (COMTRADE) y Comisión Nacional de Comercio Exterior (CNCE).

* Cifras calculadas a partir de las ecuaciones descritas en la sección IV de este artículo. MOI: manufacturas de origen industrial. 


\section{V}

\section{Análisis de las ventajas comparativas reveladas (VCR) dentro del rubro de las MOI}

El desempeño de los principales sectores de las MOI asume un papel fundamental dentro del comercio exterior argentino en relación con su media global. Subsiste una gran dependencia tecnológica, que se evidencia en una estrecha vinculación entre el nivel de actividad y las importaciones industriales de bienes intermedios y de capital. A pesar de que las exportaciones de MOI mostraron un notable crecimiento durante la década, su déficit comercial ha aumentado a lo largo de esta debido a un incremento aún mayor de sus importaciones. De allí la relevancia de evaluar la evolución que presentan los principales sectores para los efectos de comprender cuáles son las principales transformaciones que estos experimentaron dentro de las MOI a nivel global.

Para ello, en este trabajo se ha elaborado el índice de ventajas comparativas reveladas de las MOI $\left(\mathrm{VCR}_{\mathrm{MOI}}\right)$, es decir, de VCR en el interior de las MOI, de manera de considerar la evolución de cada sector en relación con la media de dicho universo (véase la subsección 1c) de la sección IV). Esta reelaboración permite comprender las modificaciones ocurridas dentro de las MOI y hacer abstracción del gran peso de los sectores de productos primarios y manufacturas de origen agropecuario en los niveles y la evolución de las VCR de las MOI.

A partir de esta metodología, en la presente sección se analizará el caso de 16 sectores seleccionados sobre la base de su marcada ponderación dentro del comercio exterior o por presentar un comportamiento muy dinámico. Estos sectores acaparan el $89 \%$ de las exportaciones de MOI, y el 76\% de las importaciones, en contraposición al $45 \%$ que representan en términos de valor agregado bruto (VAB) de este rubro, lo que demuestra su manifiesta interacción con el comercio exterior respecto de su incidencia en la producción local. Para analizar el señalado comportamiento sectorial se utilizó la siguiente categorización:

- Sectores con ventajas comparativas reveladas (VCR) dentro del universo de las manufacturas de origen industrial (MOI)

- Sectores con desventajas comparativas reveladas (DCR) leves dentro del universo de las MOI

- Sectores con DCR elevadas dentro del universo de las MOI

\section{Sectores con VCR dentro del universo de las MOI}

Estos sectores presentan las mejores posiciones como contribución al saldo dentro de las MOI, según queda reflejado en índices de $\mathrm{VCR}_{\mathrm{MOI}}$ superiores a cero ${ }^{9}$ (véase el gráfico 8). Presentan, en general, niveles no muy significativos de penetración importadora en el mercado local (por debajo del 40\%, excepto en automóviles), así como mejoras en sus saldos comerciales (véase el cuadro A.1 del anexo I).

El sector de los automóviles muestra un notable salto exportador durante el último lustro $(21,8 \%$ de crecimiento anual promedio), lo que le ha permitido prácticamente alcanzar el equilibrio comercial. Pero si se le suma el peso de las piezas para vehículos, el sector como un todo continúa siendo comercialmente deficitario (véase la sección $\mathrm{V}$, subsección 2). Cabe señalar que tanto el mercado de repuestos como el de vehículos terminados son muy dependientes de las estrategias globalizadoras de las empresas multinacionales ${ }^{10}$ que consideran una división del trabajo en cuanto a insumos y productos a nivel regional. En consecuencia, la incidencia del Brasil como destino es muy significativa, ya que hoy representa el $81 \%$ de las ventas de vehículos automotores.

El sector de productos de metales no ferrosos aparece ligado al comportamiento de la minería y su gran crecimiento en el último lustro, con especial referencia al oro y el aluminio. El oro en bruto representa en la actualidad el $89 \%$ del superávit comercial de este rubro y explica que el sector pasara de ser deficitario hacia fines de los años noventa, a ser superavitario en 2.247 millones de dólares en la actualidad. El aluminio primario aparece vinculado a la industria del embalaje

\footnotetext{
${ }^{9}$ Aunque algunos sectores presenten balances comerciales negativos (automóviles y químicos), su desempeño comercial es claramente superior a la media de la industria de MOI, lo que se refleja en índices de $\mathrm{VCR}_{\mathrm{MOI}}$ positivos dentro de dicho universo.

10 Precisamente, en un estudio del Instituto Nacional de Tecnología Industrial (INTI) (Queipo, 2008) se plantea que el país cuenta con potencialidad para crecer en el abastecimiento de repuestos para vehículos y piezas electrónicas, pero esta se ve restringida por las señaladas estrategias globalizadoras implementadas por las empresas terminales para proveerse desde el exterior.
} 
GRÁFICO 8

Argentina: evolución de las $\mathrm{VCR}_{\mathrm{MOI}}$ en sectores con ventajas comparativas relativas al universo de las MOI, 1998-2010

(Índice de valores absolutos)*

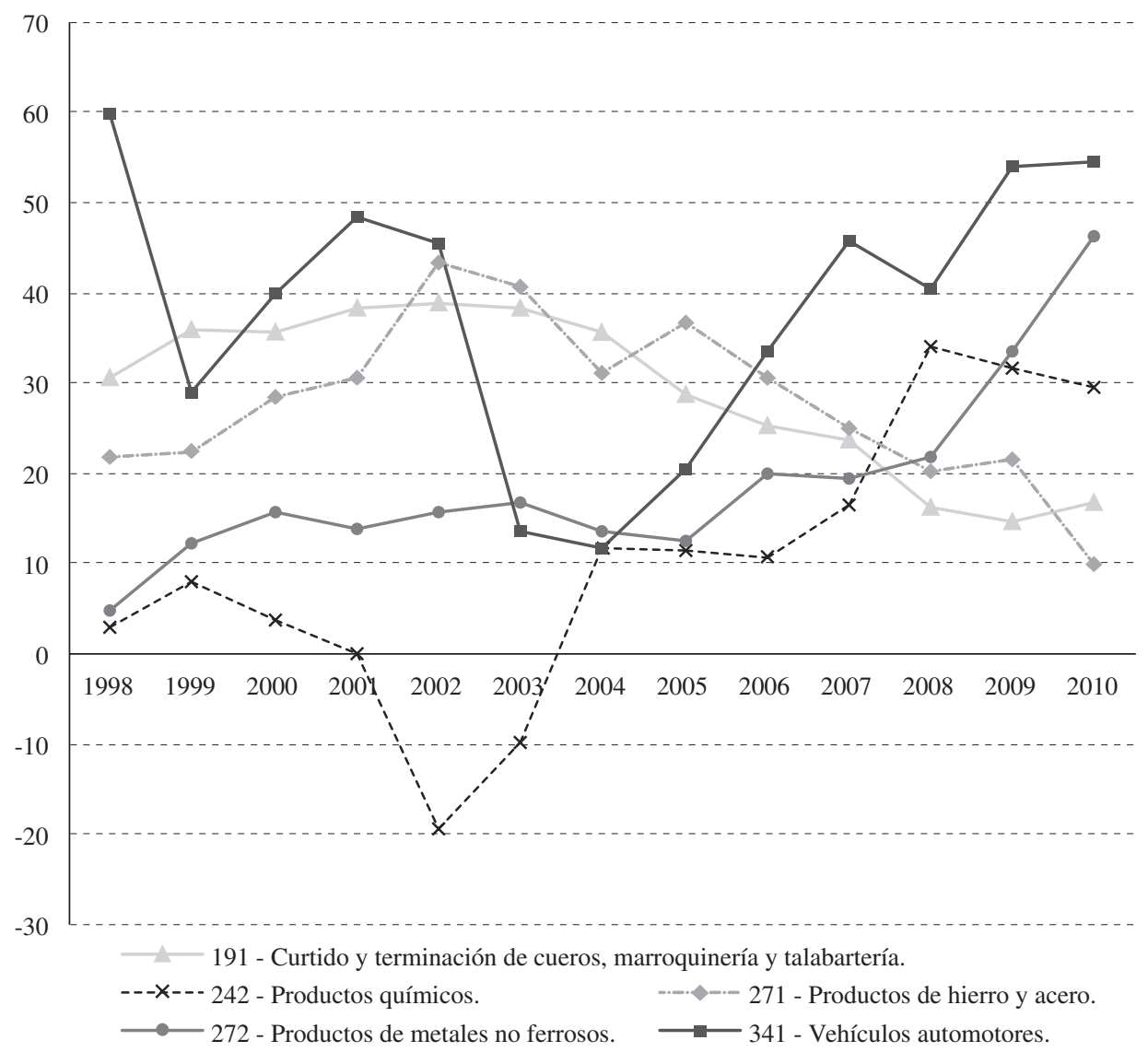

Fuente: elaboración propia sobre la base de Instituto Nacional de Estadística y Censos (INDEC), Base de datos estadísticos sobre el comercio de mercaderías (COMTRADE) y Comisión Nacional de Comercio Exterior (CNCE).

* Cifras calculadas a partir de las ecuaciones descritas en la sección IV de este artículo. MOI: manufacturas de origen industrial.

$\mathrm{VCR}_{\mathrm{MOI}}$ : índice de ventajas comparativas reveladas de las MOI.

(packaging), el transporte y la construcción, y mostró un desempeño muy dinámico con ganancias de ventajas comparativas y de participación (market share) en un mercado internacional en expansión.

Dentro de los productos químicos existen dos subsectores claramente preponderantes: el del biodiésel, producto que se vio favorecido por el diferencial de retenciones con respecto al aceite de soja (su insumo principal) ${ }^{11}$. Asimismo, las condiciones del mercado

${ }^{11}$ La protección efectiva a la producción de biodiésel a partir de aceite de soja fue del 57,4\% para el promedio del período 2008-2010. Más detalles pueden verse en Bekerman y Dulcich (2012). externo se volvieron favorables a este producto debido a los cortes mínimos de biocombustibles impuestos en la Unión Europea, así como al subsidio a la mezcla de diésel con biodiésel establecido en los Estados Unidos de América a partir de 2005.

Por otra parte, el sector farmacéutico mantiene su situación como rubro de alta tecnología con mayor desarrollo en el país, y representa alrededor del 4,5\% del valor bruto de producción (VBP) industrial. Un rasgo particular de este sector observado en la Argentina, en contraste con otros países latinoamericanos, es el predominio de empresas de capital nacional en el abastecimiento del mercado interno. Durante la posconvertibilidad, el sector mostró un comportamiento 
muy dinámico, tanto con respecto al mercado interno como a las exportaciones, que crecieron al $15 \%$ anual en el último lustro. Sin embargo, el incremento de la producción local no fue suficiente para cubrir la expansión de la demanda interna, por lo que aumentó la penetración de importaciones en el consumo aparente y el déficit comercial del sector. Su principal debilidad competitiva radica en la producción de principios activos, que son casi totalmente importados y representan la tercera parte de sus importaciones. Asimismo, existe una acentuada propensión a importar por parte de las empresas filiales de multinacionales, ya que las empresas de capital nacional muestran, en contraste, un superávit comercial (véase CILFA, 2008). En tal sentido, cabe destacar que en los últimos años han crecido significativamente un conjunto de empresas locales de menor tamaño relativo sobre la base de inversiones en tecnología y aumentos de escala, logrando de esta forma la inserción de sus productos en el mercado latinoamericano (CEP, 2009).

La pronunciada competitividad externa que muestran los productos de hierro y acero se debe principalmente al subsector de tubos sin costura para oleoductos o gasoductos, que pasó del $33 \%$ al $51 \%$ del valor exportado sectorial durante la última década. Es interesante remarcar que la competitividad exportadora, altamente concentrada en dichos tubos sin costura para la extracción de petróleo o gas, se origina en una única empresa: Siderca, que se posiciona como el principal proveedor mundial de tubos sin costura y que exportó en el último lustro casi el $70 \%$ de su producción. Esto se traduce en que la Argentina se posicione como un gran proveedor mundial de tubos sin costura, y ocupe el cuarto lugar en el comercio internacional (con el 6,5\% del mercado en el período 2005-2009), luego de China (20\%), el Japón (15,5\%) e Italia (6,9\%), e incluso por sobre países con robusta tradición en el sector siderúrgico, como Alemania $(6,4 \%)$ y los Estados Unidos de América $(5,7 \%)^{12}$.

\section{Sectores con desventajas comparativas reveladas leves dentro del universo de las Mol}

Se incluyen aquí sectores que presentan comportamientos muy diversos y, en algunos casos, mayores niveles de volatilidad que en los grupos anteriores. Esa volatilidad se observa especialmente en dos sectores: partes y accesorios para la industria automotriz y fibras manufacturadas (véase el gráfico 9).

12 Base de datos estadísticos sobre el comercio de mercaderías (COMTRADE).
Las partes y accesorios para la industria automotriz representan el 10\% del déficit de MOI y el $90 \%$ del de la cadena automotriz. Si bien muestran un veloz incremento en sus exportaciones a lo largo de la década (9,6\% anual), el deterioro de sus ventajas comparativas se vincula al fuerte crecimiento de las importaciones (17,3\% promedio anual en el último lustro). Por otra parte, tanto el sector de partes y accesorios como el de vehículos finales presentan un notable incremento en los niveles de importaciones sobre consumo aparente (véase el cuadro A.1 del anexo I), lo que refleja una creciente complementariedad productiva a nivel regional derivada de las estrategias de las multinacionales presentes en el Brasil y la Argentina. Como ya se ha destacado, la reducción en el déficit comercial registrado por el sector de vehículos finales no fue suficiente para contrarrestar el saldo negativo en aumento que muestran las partes o piezas.

El sector de radios, estéreos, televisores y grabadoras muestra también un muy significativo salto en las importaciones sobre consumo aparente, participación que llegó a superar el 70\% (véase el cuadro A1 del anexo I), junto con un nivel decreciente de sus exportaciones. El complejo electrónico registró un considerable crecimiento de su producción física durante la posconvertibilidad al amparo de la protección cambiaria y del régimen de promoción de Tierra del Fuego. Pero su expansión no alcanzó a cubrir los mayores niveles de demanda, ni fue suficiente para generar encadenamientos productivos "hacia atrás" dentro de la cadena, falencia especialmente notable en segmentos de mayor sofisticación tecnológica. En este sentido, la electrónica de consumo -particularmente, la fabricación de receptores de radio y televisión- mostró un gran dinamismo en sus ventas, pero un bajo grado de integración nacional a partir de la importación de componentes. Fue así como la recuperación y el crecimiento del sector durante la posconvertibilidad se produjeron de la mano con un aumento aun mayor de su déficit comercial (véase el cuadro A1 del anexo I) ${ }^{13}$.

El sector de instrumentos médicos, ópticos, de precisión y relojes fue prácticamente desmantelado durante la convertibilidad, sufriendo una aguda caída de sus niveles de producción entre 1991 y 2002. No obstante, durante la posconvertibilidad ha mostrado un gran dinamismo orientado al mercado interno e

13 El subsector mejor posicionado en términos exportadores es el de estéreos para automóviles, que representa el $79 \%$ de las poco significativas exportaciones sectoriales, mientras que por parte de las importaciones, los televisores y monitores registran el $33 \%$ entre 2008 y 2010. 
GRÁFICO 9

Argentina: evolución de las $\mathrm{VCR}_{\mathrm{MOI}}$ en sectores con DCR leves relativas al universo de las MOI, 1998-2010

(Índice de valores absolutos)*

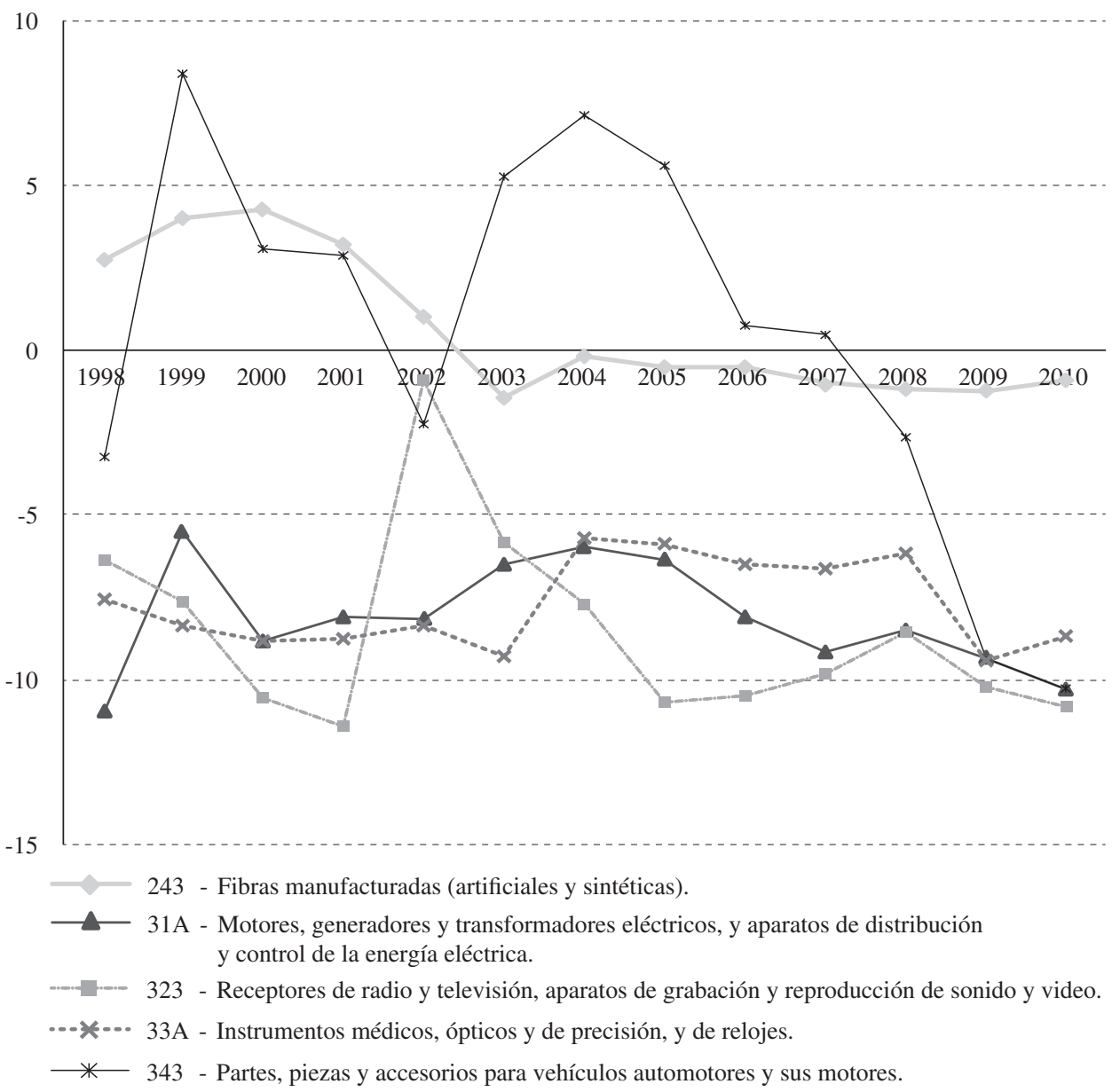

Fuente: elaboración propia sobre la base de Instituto Nacional de Estadística y Censos (INDEC), Base de datos estadísticos sobre el comercio de mercaderías (COMTRADE) y Comisión Nacional de Comercio Exterior (CNCE).

* Cifras calculadas a partir de las ecuaciones descritas en la sección IV de este artículo.

$\mathrm{VCR}_{\mathrm{MOI}}$ : ventajas comparativas reveladas de las MOI.

DCR: desventajas comparativas reveladas.

incrementado su participación en el empleo industrial dando indicios de sustitución de importaciones. Pero la evolución de sus $\mathrm{VCR}_{\mathrm{MOI}}$ muestra una clara volatilidad que puede estar ligada a exportaciones esporádicas realizadas a nuevos destinos (como República Bolivariana de Venezuela), al tiempo que ratifica al Brasil como el principal socio importador. Sin embargo, este sector mantiene elevados niveles de importaciones sobre consumo aparente (superiores al 70\%), así como un déficit comercial creciente durante el último lustro (véase el cuadro A1 del anexo I).

\section{Sectores con mayores desventajas comparativas reveladas dentro del universo de las $\mathrm{MOI}$}

Los sectores que muestran las mayores desventajas comparativas reveladas en relación con el universo de las MOI aparecen en el gráfico 10. Estos sectores se encuentran vinculados a los bienes de capital (maquinaria de uso general y especial, y maquinaria de oficina e informática) y a insumos industriales (las sustancias químicas básicas). Asimismo, en esta categoría también se encuentra el sector de tubos, válvulas, transmisores 
de radio y televisión y aparatos de telefonía, que se compone tanto de insumos como de bienes de consumo final, especialmente los teléfonos celulares, que inciden fuertemente en el comercio del sector.

$\mathrm{Al}$ ahondar en el estudio de los sectores específicos de esta categoría, se observa que las maquinarias presentan niveles superiores al 50\% de penetración importadora, y que incluso alcanzan al $90 \%$ en el caso de maquinaria de informática. Asimismo, todos los sectores presentan déficits comerciales crecientes, que revelan una continuidad de la acentuada dependencia de la oferta extranjera para abastecer los insumos y bienes de capital que requiere la actividad económica interna (véase el cuadro A1 del anexo I ).

Dentro de las maquinarias se incluyen sectores que requieren innovaciones continuas debido a que experimentan procesos de rápida obsolescencia. Las maquinarias de uso general, que representan un $10 \%$

GRÁFICO 10

\section{Argentina: evolución de las $\mathrm{VCR}_{\mathrm{MOI}}$ en sectores con DCR elevadas relativas al universo de las MOI, 1998-2010 \\ (Índice de valores absolutos)*}

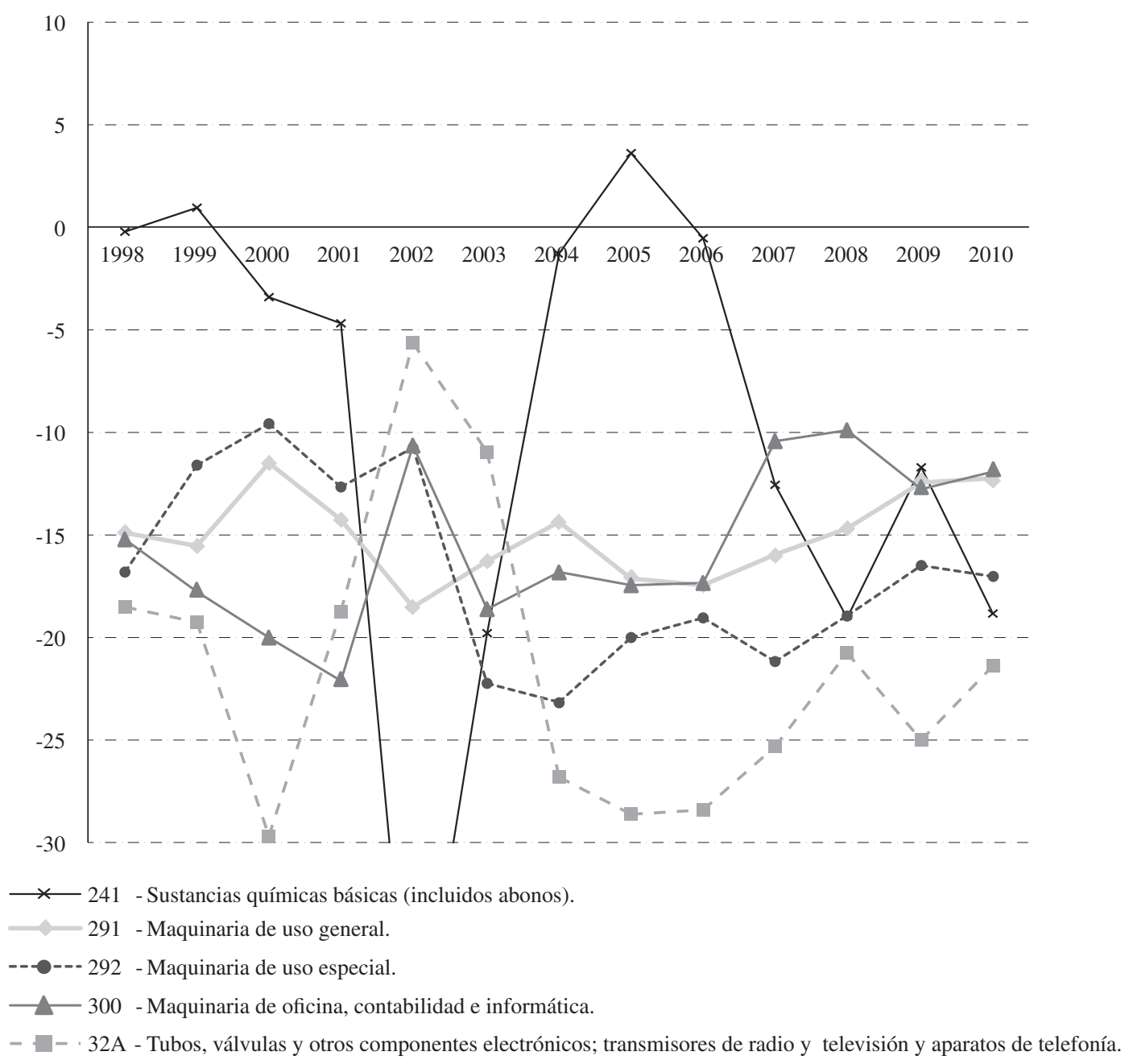

Fuente: elaboración propia sobre la base de Instituto Nacional de Estadística y Censos (INDEC), Base de datos estadísticos sobre el comercio de mercaderías (COMTRADE) y Comisión Nacional de Comercio Exterior (CNCE).

* Cifras calculadas a partir de las ecuaciones descritas en la sección IV de este artículo.

$\mathrm{VCR}_{\mathrm{MOI}}$ : ventajas comparativas reveladas de las MOI.

DCR: desventajas comparativas reveladas. 
del déficit comercial de las MOI, muestran una marcada diversificación de sus importaciones. Dentro de sus distintos subsectores, las mayores importaciones netas entre 2008 y 2010 corresponden a bombas y compresores de aire, seguidos por equipos de aire acondicionado y centrifugadoras. Como contrapartida, el único sector con saldo comercial positivo es el de las turbinas hidráulicas. Por otra parte, dos de los subsectores más dinámicos son la máquinas para el tratamiento de materias mediante el cambio de temperatura (calentadoras, pasteurizadoras, secadoras, esterilizadoras, enfriadoras, y otras) y aquellas para elevación, carga, descarga o manipulación (ascensores, transportadores, escaleras mecánicas, entre otras), cuyas importaciones netas se han reducido en un $40 \%$ durante la década y representan conjuntamente el 10\% del valor exportado sectorial en la actualidad.

La maquinaria de uso especial, que presenta también una gran desventaja comparativa (véase el gráfico 10), registra una leve recuperación a partir de 2007. Esta situación fue impulsada por dos subsectores ligados a la maquinaria agrícola: las cosechadoras (con un crecimiento del $30 \%$ promedio anual de las exportaciones durante el último lustro) y las sembradoras y arados (con un 31,4\%). La conjunción de un tipo de cambio competitivo y el auge del precio de los productos básicos (commodities) marcó un nuevo escenario favorable para estos subsectores durante la posconvertibilidad, tanto en las condiciones de oferta como de demanda. Por el contrario, en el segmento de tractores de uso agrícola, la pérdida de capacidades productivas sufrida durante la crisis de la convertibilidad impidió una respuesta local a la demanda del agro, que fue cubierta con importaciones sobre todo desde el Brasil.

En el caso de la maquinaria informática y de procesamiento de datos, su desventaja estructural presenta una leve mejoría a partir de 2008. Pese a ser un sector con una casi total penetración importadora ( $90 \%$ del consumo aparente), la relevancia de su déficit comercial dentro del conjunto de las MOI se redujo del $12 \%$ en el período de salida de la crisis, al 5\% en la actualidad. Pero en un estudio sectorial del Instituto Nacional de Tecnología Industrial (INTI) se señala que la Argentina difícilmente podrá incrementar el valor agregado nacional en esta rama en el mediano plazo, ni penetrar en los segmentos más dinámicos del mercado internacional, como hardware informático y telecomunicaciones (Queipo, 2008).

Uno de los sectores que registra las mayores oscilaciones a lo largo del período es el de las sustancias químicas básicas. Hacia fines de la década de 2000 muestra un pronunciado incremento de las importaciones vinculadas al crecimiento del agro, que fue especialmente promovido por los abonos y diversos productos químicos orgánicos (que en conjunto representan el 78\% del déficit actual del sector). En el último lustro las exportaciones de estos dos subsectores han caído un $10 \%$ promedio anual, mientras que las importaciones crecieron al $8 \%$ promedio anual. Sin embargo, no se observa un aumento significativo en la participación de las importaciones sobre el consumo aparente, lo que revela un creciente papel de la oferta doméstica en la provisión del mercado interno (véase el cuadro A1 del anexo I ).

El sector de tubos, válvulas y otros componentes electrónicos y aparatos de telefonía muestra los efectos de la falta de continuidad histórica en las políticas de desarrollo tecnológico. Hasta mediados de la década de 1970, se fabricaba en la Argentina una variedad considerable de partes y componentes electrónicos que abastecían la demanda local, principalmente de televisores y de audio. Pero los posteriores cambios en la política arancelaria y la evolución de la tecnología hacia componentes cada vez más complejos — sumados a la falta de continuidad en los esfuerzos de fabricación de dispositivos semiconductores, tanto en el sector público (INTI-Instituto de Investigaciones Científicas y Técnicas de las Fuerzas Armadas CITEFA) como en el privado (FATEDivisión Electrónica) — redundaron en una oferta local casi ausente. Esta situación se profundizó durante el decenio de 1990, en que la penetración de las importaciones en el mercado interno pasó del 38\% en 1993 al 84\% en 2001. En la actualidad, este sector aparece como el de mayor desventaja comparativa en relación con el comercio de MOI. Las importaciones corresponden mayoritariamente a los teléfonos celulares, cuya demanda interna aparece prácticamente cubierta por oferta extranjera (véase el cuadro A1 del anexo I). Las exportaciones sectoriales son prácticamente insignificantes, por lo que el sector muestra un creciente déficit que representa el 10\% del déficit comercial de las MoI. 


\section{VI}

\section{Contenido tecnológico, productividad y desempeño exportador de los distintos sectores de las MOI}

La evolución que se observa en las VCR de la economía argentina según su contenido tecnológico puede apreciarse en el gráfico $11^{14}$. Se advierte claramente una ventaja comparativa altamente concentrada en productos primarios (aunque decreciente en los últimos años), seguida de los productos agroindustriales, que contrarrestan dicha caída. Esto está fundamentado en el ya destacado desarrollo de los primeros eslabones de elaboración de la cadena agroalimentaria, como la producción de aceites, harinas y alimentación animal mediante el prensado de granos y oleaginosas.

14 La clasificación de contenido tecnológico del comercio está basada en la matriz de correspondencias de la Comisión Nacional del Comercio Exterior (CNCE).
En contraposición, todos los sectores manufactureros presentan desventajas comparativas, que se vuelven más pronunciadas en los de alto contenido tecnológico. Con respecto a los eslabones de mediana intensidad tecnológica, la desventaja comparativa es claramente más notoria en las industrias intensivas en ingeniería con respecto a las de procesos, lo que podría revelar la persistencia de una especialización del entramado industrial sesgada hacia los denominados "commodities industriales".

Para realizar una clasificación del contenido tecnológico que presentan los principales sectores de MoI y según las tres categorías consideradas en la sección $\mathrm{V}$, en el cuadro 1 se presenta una caracterización tecnológica sectorial a nivel nacional e internacional, de acuerdo con las clasificaciones definidas por el Centro de

GRÁFICO 11

Argentina: evolución de las ventajas comparativas reveladas (VCR) por contenido tecnológico

(Índice en valores absolutos)*

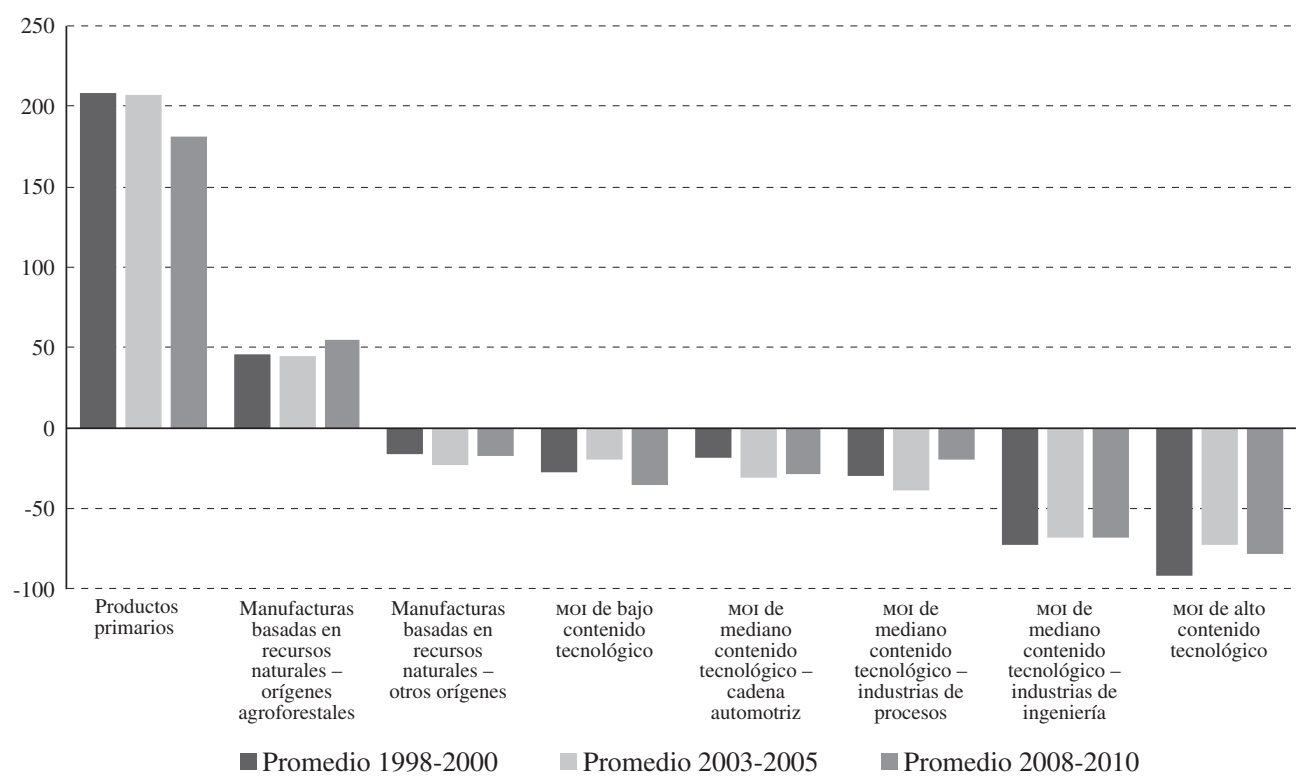

Fuente: elaboración propia sobre la base de Instituto Nacional de Estadística y Censos (INDEC), Base de datos estadísticos sobre el comercio de mercaderías (COMTRADE) y Comisión Nacional de Comercio Exterior (CNCE).

* Cifras calculadas a partir de las ecuaciones descritas en la sección IV de este artículo. 
CUADRO 1

Argentina: análisis de las VCR industriales según contenido tecnológico, 1998-2010

\begin{tabular}{|c|c|c|c|c|c|c|}
\hline $\begin{array}{l}\text { Categoría } \\
\mathrm{VCR}_{\mathrm{MOI}}\end{array}$ & Sector & $\begin{array}{l}\mathrm{VAB} / \mathrm{VBP} \\
2003 \\
\text { (porcentaje) }\end{array}$ & $\begin{array}{l}\text { Clasificación } \\
\text { tecnológica } \\
\text { CEP }\end{array}$ & $\begin{array}{c}\text { Intensidad } \\
\text { I+D en } \\
\text { Argentina } \\
\text { (porcentaje) }\end{array}$ & $\begin{array}{l}\text { Clasificación } \\
\text { OCDE }^{\mathrm{a}}\end{array}$ & $\begin{array}{c}\text { Relación } \\
\text { Argentina - } \\
\text { exterior } \\
\text { (CEP Vs OCDE) }\end{array}$ \\
\hline \multirow{5}{*}{$\begin{array}{l}\text { Ventajas } \\
\text { comparativas } \\
\text { reveladas (VCR) }\end{array}$} & $\begin{array}{l}191 \text { - Curtido y terminación de cueros, } \\
\text { marroquinería y talabartería }\end{array}$ & 19,8 & BTL & 0,06 & ВТ & Idem \\
\hline & 242 - Productos químicos & 35,6 & ATL & 0,84 & $\mathrm{AT}^{\mathrm{b}}$ & Idem \\
\hline & 271 - Productos de hierro y acero & 41,8 & MBTL & 0,11 & MBT & Idem \\
\hline & 272 - Productos de metales no ferrosos & 31,7 & MBTL & 0,24 & MBT & Idem \\
\hline & 341 - Vehículos automotores & 16,5 & BTL & 0,08 & MAT & Diferente \\
\hline \multirow{5}{*}{$\begin{array}{l}\text { Desventajas } \\
\text { comparativas } \\
\text { reveladas leves }\end{array}$} & $\begin{array}{l}243 \text { - Fibras manufacturadas (artificiales } \\
\text { y sintéticas) }\end{array}$ & 35,0 & BTL & 0,00 & MAT & Diferente \\
\hline & $\begin{array}{l}\text { 31A - Motores, generadores y transformadores } \\
\text { eléctricos, y aparatos de distribución y control de } \\
\text { la energía eléctrica }\end{array}$ & 42,7 & MBTL $^{\mathrm{c}}$ & 0,22 & MAT & Diferente \\
\hline & $\begin{array}{l}323 \text { - Receptores de radio y televisión, aparatos } \\
\text { de grabación y reproducción de sonido y video }\end{array}$ & 38,0 & MBTL & 0,19 & AT & Diferente \\
\hline & $\begin{array}{l}\text { 33A - Instrumentos médicos, ópticos y de } \\
\text { precisión, y de relojes }\end{array}$ & 46,9 & $\operatorname{ATL}^{\mathrm{d}}$ & 0,79 & AT & Idem \\
\hline & $\begin{array}{l}343 \text { - Partes, piezas y accesorios para vehículos } \\
\text { automotores y sus motores }\end{array}$ & 34,8 & ATL & 0,97 & MAT & Diferente \\
\hline \multirow{6}{*}{$\begin{array}{l}\text { Desventajas } \\
\text { comparativas } \\
\text { reveladas } \\
\text { elevadas }\end{array}$} & $\begin{array}{l}\text { 241A - Sustancias químicas básicas } \\
\text { (excluidos abonos) }\end{array}$ & 31,1 & BTL & 0,08 & MAT & Diferente \\
\hline & $\begin{array}{l}\text { 241B - Abonos y demás productos químicos } \\
\text { de uso agropecuario }\end{array}$ & 60,8 & BTL & 0,08 & MAT & Diferente \\
\hline & 291 - Maquinaria de uso general & 40,9 & MATL & 0,36 & MAT & Idem \\
\hline & 292 - Maquinaria de uso especial & 41,0 & MATL & 0,44 & MAT & Idem \\
\hline & $\begin{array}{l}300 \text { - Maquinaria de oficina, contabilidad } \\
\text { e informática }\end{array}$ & 40,0 & ATL & 1,79 & AT & Idem \\
\hline & $\begin{array}{l}32 \mathrm{~A} \text { - Tubos, válvulas y otros componentes } \\
\text { electrónicos, transmisores de radio y televisión } \\
\text { y aparatos de telefonía }\end{array}$ & 32,1 & $\mathrm{ATL}^{\mathrm{e}}$ & 0,59 & AT & Idem \\
\hline \multicolumn{2}{|c|}{ Promedio de manufacturas de origen industrial (MOI) } & 34,2 & & & & \\
\hline
\end{tabular}

Fuente: elaboración propia sobre la base de Instituto Nacional de Estadística y Censos (INDEC) y Centro de Estudios para la Producción (CEP).

Nota: valor agregado bruto (VAB) / valor bruto de producción (VBP) de 243 construido como promedio de 241 y 242 (elaboración propia sobre la base de las fuentes indicadas).

Nomenclatura según clasificación del Centro de Estudios para la Producción (CEP): BTL = baja tecnología local, MBTL = media baja tecnología local, MATL = Media alta tecnología local, ATL = Alta tecnología local

Nomenclatura según clasificación de la Organización de Cooperación y Desarrollo Económicos (OCDE): BT = baja tecnología, MBT = media baja tecnología, MAT $=$ media alta tecnología, $\mathrm{AT}=$ alta tecnología .

VCR: ventajas comparativas reveladas.

$\mathrm{VCR}_{\mathrm{MOI}}$ : ventajas comparativas reveladas de las MOI.

a Según Loschky (2008).

b La intensidad de I+D en productos químicos (242) según la OCDE corresponde a productos farmacéuticos (subsector 2423, perteneciente al 242). Fuente: Centro de Estudios para la Producción (CEP).

c Clasificado según la intensidad de I+D Arg promedio de los sectores 311 y 312, que componen el sector 31A; y utilizando la metodología del CEP (elaboración propia).

d Clasificado según la Intensidad I+D Arg promedio de los sectores 331 y 332, que componen el sector 33A; y utilizando la metodología del CEP (elaboración propia).

e Clasificado según la Intensidad I+D Arg promedio de los sectores 321 y 322, que componen el sector 32A; y utilizando la metodología del CEP (elaboración propia). 
Estudios para la Producción (CEP) ${ }^{15}$ y la Organización de Cooperación y Desarrollo Económicos (OCDE) ${ }^{16}$, respectivamente.

En el cuadro 1 se puede observar que dentro de la primera categoría, aquella que muestra a los sectores mejor posicionados dentro de las MoI, solo hay un sector catalogado como de alta tecnología según ambas clasificaciones y se refiere a los productos químicos. Vale decir que los sectores con $\mathrm{VCR}_{\mathrm{MOI}}$ positivas presentan, en general, un mediano o bajo contenido tecnológico.

Por otra parte, el sector de vehículos automotores muestra una clasificación tecnológica distinta entre las realizadas por la OCDE y el CEP. Esto puede explicarse debido al hecho de que este sector está dominado por empresas multinacionales, cuya dinámica puede conducirlas a no desarrollar tecnología allí donde poseen ciertos nodos de producción. Esto puede vincularse con que la relación entre el valor agregado y el valor bruto de producción (VBP) es significativamente menor que la del resto de los sectores, lo que se corresponde con el ya señalado alto nivel de piezas importadas.

Esas diferencias en la clasificación tecnológica vuelven a presentarse en otros sectores que registran una ingente participación de empresas multinacionales, o donde se recurre a la tecnología importada. Esta situación

15 La clasificación del CEP abarca cuatro subgrupos de intensidad de investigación y desarrollo (I+D) local. Se basa en el gasto para el año 2004 y en I+D local sobre facturación de los distintos sectores en relación con el promedio de dicho parámetro a nivel nacional (véase CEP, 2008). Pero tales gastos sectoriales pueden diferir de los gastos promedio a nivel mundial. Por lo tanto, esa clasificación puede que no capte si un sector utiliza tecnología de punta proveniente del exterior, como puede suceder cuando predominan empresas multinacionales que invierten en I+D en países desarrollados y luego transfieren ese conocimiento a países en desarrollo.

16 La categorización del contenido tecnológico sectorial pertenece a Hatzichronoglou (1997), y fue luego actualizada por OCDE (2005) y Loschky (2008). se encuentra en todos los sectores que muestran niveles de desventajas comparativas leves dentro del universo de MOI, con excepción de los instrumentos médicos.

A su vez, las maquinarias y los tubos, válvulas y otros componentes electrónicos que, como ya se subrayó, poseen una gran desventaja comparativa con respecto al universo de las MOI y dependen manifiestamente de la oferta importada, pertenecen según ambas clasificaciones a las categorías de medio y alto contenido tecnológico.

A nivel de las variaciones en los niveles de productividad, el cuadro 2 revela que dentro de los sectores con mayores $\mathrm{VCR}_{\mathrm{MOI}}$ se incluyen aquellos que tuvieron menores aumentos de productividad durante la década (con la excepción de productos de metales no ferrosos), en relación con los pronunciados crecimientos que se observan en sectores de las MOI con desventajas comparativas reveladas, como motores y generadores eléctricos, receptores de radio y televisión, abonos y maquinaria de uso general. Pero los sectores con $\mathrm{VCR}_{\mathrm{MOI}}$ se encuentran muy cerca de la frontera internacional en términos de proceso técnico, ya que presentan un diferencial de productividad con los Estados Unidos de América mucho menor que el correspondiente al total industrial (que ronda el 37\%). Esto permite fundamentar dichas ventajas en ese bajo diferencial con la frontera internacional, más que a partir de la expansión de la demanda internacional, como podría ser el caso de ciertos productos primarios y sus derivados. Esta cercanía de la frontera internacional tal vez pueda ayudar a explicar el menor crecimiento de la productividad con respecto a los sectores que presentan desventajas comparativas. Estos últimos muestran, en muchos casos, muy bajos niveles de productividad por obrero ocupado en comparación con sus pares de los Estados Unidos de América, lo que puede ayudar a vincular la existencia de dichas desventajas con las marcadas brechas respecto de la frontera internacional. 
CUADRO 2

Argentina: análisis de las VCR industriales según evolución de la productividad y nivel de productividad en relación con los Estados Unidos de América en 2005

\begin{tabular}{|c|c|c|c|c|}
\hline \multirow[b]{2}{*}{ Categoría $\mathrm{VCR}_{\mathrm{MOI}}$} & \multirow[b]{2}{*}{ Sector } & \multicolumn{2}{|c|}{$\begin{array}{l}\text { Variación de la productividad } \\
(1998-2000 \text { y 2008-2010) }\end{array}$} & \multirow{2}{*}{$\begin{array}{l}\text { Nivel de productividad } \\
\text { laboral en relación con } \\
\text { los Estados Unidos, } \\
2005^{\mathrm{a}} \text { (porcentaje) }\end{array}$} \\
\hline & & $\begin{array}{l}\text { Por obrero } \\
\text { ocupado } \\
\text { (porcentaje) }\end{array}$ & $\begin{array}{l}\text { Por hora } \\
\text { trabajada } \\
\text { (porcentaje) }\end{array}$ & \\
\hline \multirow{5}{*}{$\begin{array}{l}\text { Ventajas } \\
\text { comparativas } \\
\text { reveladas (VCR) }\end{array}$} & $\begin{array}{l}191 \text { - Curtido y terminación de cueros y productos } \\
\text { de marroquinería y talabartería }\end{array}$ & 12,8 & 18,1 & 124,6 \\
\hline & 242 - Productos químicos & 16,4 & 19,1 & $71,9^{\mathrm{b}}$ \\
\hline & 271 - Productos de hierro y acero & 39,8 & 32,1 & 80,7 \\
\hline & 272 - Productos de metales no ferrosos & 105,4 & 109,7 & 41,6 \\
\hline & 341 - Vehículos automotores & 44,0 & 31,9 & $61,0^{\mathrm{c}}$ \\
\hline \multirow{5}{*}{$\begin{array}{l}\text { Desventajas } \\
\text { comparativas } \\
\text { reveladas leves }\end{array}$} & 243 - Fibras manufacturadas (artificiales y sintéticas) & $-24,1$ & $-15,1$ & $40,9^{d}$ \\
\hline & $\begin{array}{l}\text { 31A - Motores, generadores y transformadores } \\
\text { eléctricos, y aparatos de distribución y control de } \\
\text { la energía eléctrica }\end{array}$ & 52,4 & 61,2 & $3,8^{\mathrm{e}}$ \\
\hline & $\begin{array}{l}323 \text { - Receptores de radio y televisión, aparatos de } \\
\text { grabación y reproducción de sonido y video }\end{array}$ & 78,8 & 74,2 & 14,3 \\
\hline & $\begin{array}{l}\text { 33A - Instrumentos médicos, ópticos y de precisión, } \\
\text { y de relojes }\end{array}$ & 52,4 & 55,8 & 9,0 \\
\hline & $\begin{array}{l}343 \text { - Partes, piezas y accesorios para vehículos } \\
\text { automotores y sus motores }\end{array}$ & 13,1 & 21,3 & $61,0^{\mathrm{c}}$ \\
\hline \multirow{6}{*}{$\begin{array}{l}\text { Desventajas } \\
\text { comparativas } \\
\text { reveladas elevadas }\end{array}$} & $\begin{array}{l}\text { 241A - Sustancias químicas básicas (excluidos } \\
\text { abonos) }\end{array}$ & 33,7 & 33,1 & $71,9^{\mathrm{b}}$ \\
\hline & $\begin{array}{l}\text { 241B - Abonos y demás productos químicos de } \\
\text { uso agropecuario }\end{array}$ & 87,7 & 89,7 & $71,9^{b}$ \\
\hline & 291 - Maquinaria de uso general & 56,3 & 61,6 & $20,5^{f}$ \\
\hline & 292 - Maquinaria de uso especial & 40,3 & 46,7 & $20,5^{f}$ \\
\hline & $\begin{array}{l}300 \text { - Maquinaria de oficina, contabilidad e } \\
\text { informática }\end{array}$ & $-48,1$ & $-45,5$ & $20,5^{\mathrm{f}}$ \\
\hline & $\begin{array}{l}\text { 32A - Tubos, válvulas y otros componentes } \\
\text { electrónicos; transmisores de radio y televisión } \\
\text { y aparatos de telefonía }\end{array}$ & $-45,0$ & $-43,0$ & $3,8^{\mathrm{e}}$ \\
\hline \multicolumn{2}{|c|}{ Promedio sectores seleccionados } & 32,2 & 34,4 & 44,9 \\
\hline \multicolumn{2}{|c|}{$\begin{array}{l}\text { Promedio industrial (considera tanto las manufacturas de origen } \\
\text { agropecuario como las industriales). }\end{array}$} & 35,8 & 41,1 & 36,9 \\
\hline
\end{tabular}

Fuente: elaboración propia sobre la base de Centro de Estudios para la Producción (CEP), y J. Katz y G. Bernat, "Creación de empresas, crecimiento en la productividad y cambio estructural como respuesta a una modificación en la política macroeconómica. Evidencia para la Argentina", Revista de Economía Política de Buenos Aires, año 5, volúmenes Nº 9 y 10, Buenos Aires, Universidad de Buenos Aires, 2011.

a Como porcentaje del producto medio por obrero ocupado (a precios de 1985).

b Corresponde al sector agregado "Químicos".

c Corresponde al sector agregado "Equipos de transporte".

d Corresponde a un promedio ponderado de los sectores "Textiles" (66,7\%) y "Productos plásticos" (33,3\%).

e Corresponde al sector agregado "Equipo electrónico".

f Corresponde al sector agregado "Maquinaria y equipo". 


\section{VII}

\section{Síntesis y conclusiones}

Durante la última década, el patrón de especialización internacional de la economía argentina no muestra considerables modificaciones a nivel de los grandes rubros. Los productos primarios y las MOA explican gran parte de la competitividad externa y del superávit comercial. Sin embargo, dentro de este contexto, cabe destacar cambios significativos en la composición de los productos primarios y de las MOA, en los flujos comerciales por origen y destino, así como una aguda caída en las ventajas comparativas que presentan los combustibles.

Estas transformaciones han sido en gran medida el resultado del acentuado incremento de los precios relativos de los productos básicos, dada la creciente demanda de los países asiáticos. No obstante, sin entrar en un análisis de equilibrio general, se aprecia una situación de superávit comercial incluso descontando la evolución favorable de los precios relativos externos, en un contexto de notable crecimiento como el que tuvo lugar en la economía argentina durante los últimos años.

Pero las MOI mantienen una situación de desventaja comparativa y de déficit estructural y creciente, dado que en la economía argentina aún no se ha podido reducir la ostensible dependencia que muestra entre el nivel de actividad y las importaciones de ciertas maquinarias, insumos, y partes y piezas. Asimismo, tampoco se ha podido sustituir satisfactoriamente la oferta importada ante la gran demanda de ciertos bienes finales, especialmente de alto contenido tecnológico, como televisores y celulares.

Del mismo modo, en la composición de las exportaciones de MOI se constata un marcado crecimiento en actividades que gozaron de regímenes favorables, como el oro y el aluminio en formas primarias, y el biodiésel. Cabe destacar también el caso de la industria automotriz, beneficiada por un régimen especial dentro de las reglas del Mercado Común del Sur (MERCOSUR). Estos sectores, junto con los de tubos sin costura para petróleo y gas, son el principal fundamento del crecimiento que muestran las exportaciones de MOI a partir de la salida de la convertibilidad.

De esta forma, el patrón de especialización comercial de la Argentina se presenta aún como altamente concentrado en sectores vinculados a la renta primaria y a procesos industriales estandarizados (tanto en las MOA como en las MOI) que presentan, en general, baja diferenciación de productos y procesos, y que muestran en muchos casos una manifiesta dependencia de bienes de capital y componentes extranjeros. Sin embargo, conviene subrayar que se observa un incipiente desarrollo de competitividad externa en algunos sectores industriales de elevado contenido tecnológico, como es el caso de ciertos subsectores de la maquinaria agrícola.

Con respecto a los destinos, hay que destacar que las sustituciones de orígenes de importación en las MoI, sumadas al desplazamiento de destinos de exportación de productos primarios y de MOA, tienen como fundamento la expansión de China como actor relevante en la economía mundial. El crecimiento de la demanda china de bienes primarios y alimentos y de su oferta de bienes industriales está presionando hacia la "primarización" de las economías emergentes. Esto puede verse acentuado en el tiempo a partir de los objetivos establecidos en su último plan quinquenal, orientados a avanzar hacia segmentos industriales de mayor sofisticación tecnológica. Es importante remarcar que el mayor protagonismo que muestran China y el Brasil, como nuevos socios comerciales, se corresponde con un desplazamiento de socios comerciales tradicionales, por lo que persiste la tradicional concentración de la inserción externa argentina en pocos países.

De acuerdo con las concepciones teóricas expuestas, se puede afirmar que, de mantenerse en el futuro, esta inserción puede afectar tanto a la sustentabilidad como al nivel de crecimiento de largo plazo, en la medida en que persista la marcada dependencia del entramado industrial de la importación de bienes de capital e insumos. De igual modo, el menor crecimiento del nivel de productividad total de la economía, que implica la especialización en sectores estandarizados, genera dificultades para aumentar los salarios reales sin afectar la valorización y acumulación de capital, lo que puede llegar a acentuar la tensión distributiva. Por otra parte, la gran concentración sectorial y regional de la inserción externa de la economía argentina la vuelve dependiente de pocos mercados.

En ese contexto, y considerando los cambios que están teniendo lugar en la estructura productiva a nivel global, se plantean grandes desafíos. Se destaca la necesidad de promover una diversificación exportadora basada en la expansión de valor agregado en ramas existentes y de sectores estratégicos que puedan cumplir un papel 
de liderazgo, tomando el MERCosur como un primer paso para la realización de esa estrategia. Con el fin de cumplir estos objetivos se torna necesario, en primer lugar, impulsar una gestión macroeconómica que asegure un tipo de cambio real a objeto de promover el desarrollo productivo. Por otra parte, se necesita implementar políticas específicas que, alterando el vector de precios de libre mercado que determina la "eficiencia estática", tiendan a favorecer la diversificación exportadora. Esto requiere de un proceso de colaboración estratégica entre los sectores público y privado, que permita obtener la información necesaria para llevar adelante en forma correcta el diseño y la implementación de políticas industriales. Asimismo, es preciso un importante poder político que administre el conflicto de intereses entre distintos grupos que puede generarse ante la aplicación de dichas políticas. Complementariamente, se presenta el desafío de imponer un sistema de reciprocidad o de incentivos y castigos que aliente la inversión en sectores no tradicionales, pero que también pueda, como señala Rodrik (2005), detectar las inversiones que fracasen y generar condiciones para un sistema de captación de rentas.

Sin desestimar algunos fundamentales cambios de rumbo que se pueden observar durante los últimos años, el principal desafío con que se enfrenta hoy la Argentina es en gran medida similar al de hace dos décadas: "la necesidad de conformar una estructura productiva que mejore su inserción comercial, que incremente la generación de empleo productivo, reduciendo la heterogeneidad estructural, de modo de mejorar la distribución del ingreso y reducir la pobreza extrema" (Rosales, 1989).

\section{Bibliografía}

Agosin, M. (2009), "Crecimiento y diversificación de exportaciones en economías emergentes", Revista de la CEPAL, $\mathrm{N}^{\circ} 97$ (LC/G.2400-P), Santiago de Chile, abril.

Appleyard, D. y A. Field (1997), Economía internacional, Madrid, McGraw-Hill.

Bekerman, M. y D. Cerdeiro (2007), "Integración, crisis y patrón de especialización de la economía argentina (1994-2005)", Documento de Trabajo, $\mathrm{N}^{\circ} 16$, Buenos Aires, Centro de Estudios de la Estructura Económica (CENES).

Bekerman, M. y F. Dulcich (2012), "Transformaciones recientes en el patrón de especialización de la economía argentina”, Documento de Trabajo, $\mathrm{N}^{\circ}$ 21, Buenos Aires, Centro de Estudios de la Estructura Económica (CENES), en prensa.

Bekerman, M. y P. Sirlin (1999), "Patrón de especialización y desarrollo de la economía argentina", Documento de Trabajo, $\mathrm{N}^{\mathrm{o}}$ 4, Buenos Aires, Centro de Estudios de la Estructura Económica (CENES).

CEP (Centro de Estudios para la Producción) (2009), "La industria farmacéutica en la Argentina”, Buenos Aires, enero [en línea] http://www.cep.gov.ar/descargas_new/panorama_sector_ industria/presentaciones_sectoriales/farmacia.pdf.

(2008), "Contenido tecnológico de las exportaciones argentinas 1996-2007. Tendencias de upgrading intersectorial" [en línea] www.cep.gov.ar.

CILFA (Cámara Industrial de Laboratorios Farmacéuticos Argentinos) (2008), Trayectorias sectoriales en la industria de la postconvertibilidad. En busca de indicios de cambio estructural, Buenos Aires.

Hatzichronoglou, T. (1997), "Revision of the high-technology sector and product classification", Science, Technology and Industry Working Papers, № 1997/2, París, Organización de Cooperación y Desarrollo Económicos (OCDE).
Hausmann, R. y D. Rodrik (2003), "Economic development as selfdiscovery", Journal of Development Economics, vol. 72, $\mathrm{N}^{\circ} 2$, Amsterdam, Elsevier.

Katz, J. y G. Bernat (2011), "Creación de empresas, crecimiento en la productividad y cambio estructural como respuesta a una modificación en la política macroeconómica. Evidencia para la Argentina", Revista de Economía Política de Buenos Aires, año 5, vols. $\mathrm{N}^{\circ} 9$ y 10, Buenos Aires, Universidad de Buenos Aires.

Loschky, A. (2008), "Reviewing the nomenclature for high-technology trade. The sectoral approach" (STD/SES/WPTGS(2008)9), París, Organización de Cooperación y Desarrollo Económicos (OCDE), septiembre.

Miotti, L., C. Quenan y C. Winograd (1998), “Spécialisation internationale et intégration régionale. L'Argentine et le MERCOSUR", Économie Internationale, N $^{\circ} 74$, París, CEPII.

ocDE (Organización de Cooperación y Desarrollo Económicos) (2005), OCDE Handbook on Economic Globalisation Indicators, París.

Queipo, G. (2008), "Industria electrónica en Argentina: Situación actual y perspectivas", Buenos Aires, Área de Economía Industrial, Instituto Nacional de Tecnología Industrial (INTI).

Rodrik, D. (2005), "Políticas de diversificación económica", Revista de la CEPAL, N ${ }^{\circ} 87$ (LC/G.2287-P), Santiago de Chile, diciembre.

Rosales, O. (1989), "Marco externo, estrategias de desarrollo y ajuste estructural”, Desarrollo Económico, vol. 29, № 113, abril-junio, Buenos Aires, Instituto de Desarrollo Económico y Social (IDES).

Wade, R. (1989), "What can economics learn from East Asian success?", Annals of the American Academy of Political and Social Science, vol. 505, Thousand Oaks, Sage Publications. 
ANEXO I

CUADRO A1

Argentina: penetración importadora y saldo comercial de los sectores de las MOI considerados

\begin{tabular}{|c|c|c|c|c|c|c|}
\hline \multirow{2}{*}{ Sector } & \multicolumn{3}{|c|}{$\begin{array}{l}\text { Importaciones / consumo aparente } \\
\text { (porcentajes) }\end{array}$} & \multicolumn{3}{|c|}{$\begin{array}{c}\text { Saldo comercial } \\
\text { (en millones de dólares) }\end{array}$} \\
\hline & $\begin{array}{l}\text { Promedio } \\
1998-2000\end{array}$ & $\begin{array}{l}\text { Promedio } \\
2008-2010\end{array}$ & $\begin{array}{l}\text { Variación } \\
\text { lineal }\end{array}$ & $\begin{array}{l}\text { Promedio } \\
1998-2000\end{array}$ & $\begin{array}{l}\text { Promedio } \\
2008-2010\end{array}$ & $\begin{array}{l}\text { Variación } \\
\text { lineal }\end{array}$ \\
\hline $\begin{array}{l}191 \text { - Curtido y terminación de cueros, marroquinería } \\
\text { y talabartería }\end{array}$ & 8,4 & 11,8 & 3,4 & 723 & 755 & 33 \\
\hline $\begin{array}{l}\text { 241A - Sustancias químicas básicas (excluidos } \\
\text { abonos) }\end{array}$ & 43,9 & 45,7 & 1,8 & -1378 & -2626 & -1248 \\
\hline $\begin{array}{l}\text { 241B - Abonos y demás productos químicos de uso } \\
\text { agropecuario }\end{array}$ & 27,6 & 28,8 & 1,2 & -248 & -832 & -585 \\
\hline 242 - Productos químicos & 16,9 & 26,7 & 9,8 & -1258 & -97 & 1161 \\
\hline 243 - Fibras manufacturadas (artificiales y sintéticas) & 26,9 & 51,7 & 24,8 & 15 & -147 & -162 \\
\hline 271 - Productos de hierro y acero & 17,4 & 17,5 & 0,2 & 144 & 45 & -99 \\
\hline 272 - Productos de metales no ferrosos & 31,7 & 40,8 & 9,1 & 22 & 1384 & 1363 \\
\hline 291 - Maquinaria de uso general & 53,9 & 53,1 & $-0,8$ & -1577 & -2124 & -547 \\
\hline 292 - Maquinaria de uso especial & 48,8 & 52,4 & 3,6 & -1121 & -2151 & -1030 \\
\hline 300 - Maquinaria de oficina, contabilidad e informática & 93,0 & 97,1 & 4,1 & -1167 & -1135 & 32 \\
\hline $\begin{array}{l}323 \text { - Receptores de radio y televisión, aparatos de } \\
\text { grabación y reproducción de sonido y video }\end{array}$ & 41,4 & 70,6 & 29,2 & -553 & -1007 & -454 \\
\hline 341 - Vehículos automotores & 37,7 & 55,9 & 18,2 & -465 & -200 & 265 \\
\hline $\begin{array}{l}343 \text { - Partes, piezas y accesorios para vehículos } \\
\text { automotores y sus motores }\end{array}$ & 40,7 & 53,8 & 13,1 & -849 & -1874 & -1025 \\
\hline $\begin{array}{l}\text { 31A - Motores, generadores y transformadores } \\
\text { eléctricos, y aparatos de distribución y control de la } \\
\text { energía eléctrica }\end{array}$ & 60,8 & 64,2 & 3,4 & -693 & -1113 & -420 \\
\hline $\begin{array}{l}\text { 33A - Instrumentos médicos, ópticos y de precisión, } \\
\text { y de relojes }\end{array}$ & 67,1 & 71,4 & 4,3 & -659 & -967 & -308 \\
\hline
\end{tabular}

Fuente: elaboración propia sobre la base de Instituto Nacional de Estadística y Censos (INDEC), Base de datos estadísticos sobre el comercio de mercaderías (COMTRADE) y Comisión Nacional de Comercio Exterior (CNCE).

MOI: manufacturas de origen industrial. 
ANEXO II

Aspectos metodológicos

\section{Bases de datos y fuentes de información}

La categorización sectorial, así como la fuente de información de exportaciones sobre valor bruto de producción sectorial e importaciones sobre consumo aparente sectorial, pertenecen a las fichas sectoriales 2010 del Centro de Estudios para la Producción (CEP) $)^{17}$.

La base de datos de comercio exterior pertenece al comercio exterior argentino 1998-2009 según la Nomenclatura Común del Mercosur (NCM) a seis dígitos, sistema armonizado 2002 (Fuente: INDEC y COMTRADE).

Esta base fue convertida a la nomenclatura de la Clasificación Industrial Internacional Uniforme de todas las actividades económicas (CIUU), realizada por las Naciones Unidas, Revisión 3.1; así como a los grandes rubros, uso económico y contenido tecnológico, utilizando la matriz de correspondencias de la Comisión Nacional de Comercio Exterior (CNCE), de junio de 2003.

17 Disponibles en: http://www.cep.gov.ar/descargas_new/estadisticas/ sectores/fichas_sectoriales_2010.xls.
La transformación de los flujos de comercio exterior corriente a precios constantes de 2003 se realizó utilizando el índice de precios de las importaciones por uso económico, base 1993=100 y el índice de precios de las exportaciones por grandes rubros, base 1993=100 (Fuente: INDEC para ambos). Dichos índices fueron ponderados por el peso del uso económico o gran rubro en cada año, utilizando las bases de datos de comercio y la matriz de correspondencias de la CNCE ya citadas. Los datos macroeconómicos de producto interno bruto y composición de la demanda agregada tienen su fuente en el INDEC.

\section{Categorización sectorial}

Para la categorización de los sectores de MOI se tomaron 32 sectores según la clasificación ciIU, Revisión 3.1, a tres dígitos de desagregación, así como 10 sectores de MOI agregados según categorías por el CEP para sus fichas sectoriales. Para el análisis fueron seleccionadas 16 de estos sectores, 11 de la clasificación ciIU, Revisión 3.1, y 5 de los elaborados por el CEP, según su preponderancia en niveles o en la evolución del comercio y la producción industrial. 